\title{
Enhanced Stress Testing and Financial Stability
}

\author{
Matthew Pritsker*
}

July 30, 2012

\begin{abstract}
To date, regulatory bank stress testing in the United States has focused on ensuring the banking system is resilient to losses in one or a few stress scenarios that involve macro-economic weakness, but it is unclear how far this resilience extends beyond the stress scenarios considered. In addition, a theory of which stress-scenarios should be chosen to achieve systemic-risk reduction objectives has not yet been developed. To improve stress testing practices, this paper proposes a framework for modeling systemic risk. The framework is used to identify areas where current stress-testing practices can be improved. Based on the framework, the paper proposes a new approach for systemic risk stress-testing and recapitalization policy that ensure the banking system is robust to a wide set of shocks, but minimizes the costs of achieving robustness through better sharing of risk. In addition, the systemic risk framework is used to examine how risks should be shared among banks to achieve systemic risk reduction.
\end{abstract}

Keywords: Stress Testing, Financial Stability, Lending, Employment

${ }^{*}$ The authors is a member of the Risk and Policy Analysis Unit at the Federal Reserve Bank of Boston. I thank Burcu Bump-Duygan, Alexey Levkov, Patrick deFontnouvelle, Jean Sebastien Fontaine, Bev Hirtle, Martin Summer, Mathias Drehmann, and participants at the Harvard Finance Brown Bag, the RPA Brown Bag, the Fourth Risk Management Conference at Mont Tremblant, the 2011 System Committee Meeting on Financial Structure and Regulation, and the 2011 Federal Reserve Bank of New York / Society of Financial Econometrics Conference on Global Systemic Risk. I also thank Isaac Weingram for valuable research assistance. Matt Pritsker's contact information is as follows: ph: (617) 973-3191, email: matthew.pritsker at bos.frb.org. The views expressed in this paper are those of the author but not necessarily those of the Federal Reserve Bank of Boston or other parts of the Federal Reserve System. 


\section{Introduction}

The Great Recession underlined the role of the financial sector in real economic activity and highlighted the importance of assessing and monitoring financial stability. During the recession and the period that followed, the Federal Reserve conducted a series of stress tests, beginning with the Supervisory Capital Assessment Program (SCAP), and more recently the Comprehensive Capital Analysis and Review (CCAR). Both programs had the objective of improving financial stability through identifying vulnerabilities in banks' balance sheets, requiring more bank capital as needed, and through releasing information to the public on banks' performance. The stress tests proved to be useful in identifying capital shortfalls, and through increased capital and heightened transparency reduced investors uncertainty about the financial sector during turbulent times. ${ }^{1}$ In the aftermath of the crisis, stress testing will be employed on a regular basis in the United States. ${ }^{2}$ The European Banking Authority is also likely to continue stress testing European banks on a regular basis.

Broadly speaking there are two categories of stress-tests: micro-prudential stress tests, that are designed to assess the financial resilience of individual banks; and systemic tests that assess the resilience of the financial system. The focus of this paper is systemic tests. The financial system becomes systemically impaired when it cannot provide needed financial intermediation (FI) services to the real sector. Financial distress at a single bank will not necessarily cause systemic impairment if other institutions can step in and provide the services that cannot be provided by the distressed institution. However, if banks representing enough intermediation activity experience financial distress at the same time, then others may be not able to substitute for the lost FI services, and systemic impairment results.

This paper defines systemic risk as the risk that the financial system becomes systemically impaired. Systemic stress tests reduce systemic risk by reducing the likelihood that banks experience joint financial distress. ${ }^{3}$ To do so, one or a few adverse macro-economic scenarios are applied to all banks. Based on the banks' losses, capital is increased to ensure that the banks can together adequately weather the adverse scenarios. ${ }^{4,5}$

\footnotetext{
${ }^{1}$ Supervisors requested 10 out of 19 banks participating in SCAP to raise $\$ 75$ billion. All SCAP procedures and findings were made publically available for purposes of clarifying the SCAP process (Board of Governors of the Federal Reserve System, 2009a, 2009b). See Hirtle, Schuermann, and Stiroh (2009) for an overview of the SCAP. See Peristiani, Morgan, and Savino (2010) for an event study of analysis how the SCAP reduced uncertainty about banks.

${ }^{2}$ The Dodd-Frank Wall Street Reform and Consumer Protection Act mandates the Federal Reserve to perform annual stress tests of the major financial institutions. The institutions will also conduct their own stress tests. Institutions with total assets of at least $\$ 10$ billion will stress their portfolios once a year, while institutions with at least $\$ 50$ billion will conduct biannual tests.

${ }^{3}$ As noted above, the other way is through the provision of information.

${ }^{4}$ This paper does not take a stand on whether the capital should be privately raised or provided by the government

${ }^{5}$ The CCAR employed several stress-tests in addition to a single stress scenario applied to all banks. More specifically, in CCAR both supervisors and the banks forecasted banks' losses over a nine-quarter horizon under a baseline scenario, a stress scenario, and an adverse supervisory stress scenario. The baseline scenario was generated
} 
The benchmark for the success of a program of systemic risk stress-testing and capital setting policy is its ability to make the provision of financial intermediation services robust to the severe but plausible shocks that can affect the financial system, and to accomplish this at low cost. This notion of robustness is similar to Eric Rosengren's (2011) definition of financial stability as "the ability of the financial system to consistently supply the credit intermediation and payment services that are needed in the real economy if it is to continue on its growth path. ${ }^{6 "}$

Relative to this benchmark, there are two important areas in which systemic risk stress-testing practices in the US can be refined. First, the systemic risk stress-tests are primarily focused on stresses emanating from the macro-economy to the banks; there is not a formal method for determining what other source of shocks should be considered. Second, the US approach to systemic risk stress-testing and capital policy make the banking system robust to the stress-scenarios that are used in the test. But, because it is not part of the design, it is not clear how far the robustness extends against the other shocks that the banking system may face.

The first area in which stress-testing could be improved is that stress scenarios should be based on all of the risk exposures that banks face. During the height of the financial crisis of 2007-2009 macro-economic weakness represented one of the most important threats to the banking system; and problems with the banking system would have made the macro-economic situation even worse. Systemic risk stress-tests based on a macroeconomic scenario were used then to shore-up the banking system and the macroeconomy against this threat.

During good times, the more relevant threats to the banking system and real activity often stem not from the macroeconomy but rather from banks' other risk exposures. More specifically, Afaro et al's (2009) study of 43 financial crises found that about half of them occurred before the macroeconomy experienced adverse economic conditions. The early stages of the recent financial crisis is a good example since the problems in the financial system preceded much of the weakness in the macroeconomy. Other examples are risks that emanate from financial institutions' overseas exposures. Historical examples include bank branches of Japanese banks cut back their US lending in response to the bursting of the real estate bubble in Japan in the late 80s; debt problems in Mexico, Brazil, and Argentina in the early '80s created large losses for some US banks; more recently there is a concern that direct or indirect exposures to European sovereign debt exposure could

by the banks and reflected their expectations of the most likely path of the economy. The stress scenario was also generated by the banks and was targeted at stressing key sources of their revenue and loss. The adverse supervisory stress scenario was generated by the Federal Reserve and was intended to represent developments in the recession specified in terms of key macroeconomic indicators. Specifically, the Federal Reserve assumed a negative economic growth and a rise in unemployment for several quarters, among other developments.

${ }^{6}$ There are many other notions of financial stability or instability. Mishkin (1999), for example, defines financial instability as misallocation of capital as a result of a disruption in information flows between potential borrowers and lenders. Capital misallocation results in inefficiency in the sense that capital does not necessarily flow to those with the most productive investment opportunities. Borio and Drehmann (2009) separate financial instability from financial distress. They define financial instability as a property of financial markets that may cause financial distress. Financial distress, in turn, is an event in which losses at financial institutions affect the real economy in terms of foregone output. 
spillover to US markets and financial institutions. In all of these cases, important risk exposures and shocks could be missed if stress scenarios are chosen only based on U.S. macro-stresses without consideration of banks' exposures to all sources of risk.

The second area where stress-testing and recapitalization practices should be enhanced is that they should be explicitly designed for robustness. A robust approach ensures that the financial system is not only well capitalized and resilient against the stress scenario under consideration, but also against a much broader set of plausible shocks to the financial system.

Ensuring robustness of the financial system does not mean that the financial system should be able to weather all shocks, but rather that it should be unlikely that distress spills over from the financial system to affect the real economy. A physical analogy is useful: there will always be some floods that are large enough that they can overwhelm a dam of any size and spillover to the valley below; the robustness of the dam can be measured by the probability that it will not be overwhelmed. Similarly, the robustness of financial safeguards (such as capital buffers) can be measured by the probability or confidence that the financial sector is resilient in the sense that shocks to the financial sector will not spillover and harm the real economy. For example, a financial system is robust with confidence level 99 percent if its performance is resilient with probability of at least 99 percent.

The current US approach to systemic risk stress-testing, because it focuses on a very adverse macro scenario, is likely to provide some amount of resilience of the financial system to other plausible shocks. But the extent of robustness is unclear. Geometrically, if a set of plausible shocks that could occur with 99 percent probability lie within a closed region such as the points in a multidimensional rectangle, then an approach to stress-testing that guarantees financial system resilience to all of the points in the region is robust with at least 99 percent confidence. By contrast the current US approach guarantees resilience to the scenarios used in the stress test, but the extent to which that resilience to extends to the other types of shocks in the region that the financial system is exposed to is unclear.

This paper makes three contributions to the literature on systemic risk stress-testing. First, it analyzes systemic risk, stress-testing, and capital policy within the framework of a formal model in which the objectives of stress-testing are clearly defined. Using the model, weaknesses in current stress practices are identified, and alternative methodologies are proposed. Second, the paper introduces a new framework for systemic risk stress-testing. The framework models the financial system's ability to provide financial intermediation services to the real sector. Stress-tests and capital injections are chosen to make the financial system's ability to provide financial intermediation services robust with a high degree of confidence. ${ }^{7}$ Third, the paper proposes an additional layer of capital standards, and an information disclosure policy that are both designed to encourage better

\footnotetext{
${ }^{7}$ Put differently, our approach operationalizes Greenlaw et al's (2012) goal of using macroprudential policy to preserve the balance sheet capacity of the financial sector to support the economy.
} 
risk-sharing for systemic risk purposes.

Stress testing practice is refined in two ways. First, banks' risk exposures are used to construct scenarios. Choosing scenarios based on exposures helps to prevent important risk sources from being overlooked. Even if all potential risk sources are accounted for, it is important to use exposure information to choose the best direction of stress factor movements when forming a stress test. As a simple example of this principle, a downward move in stock prices is not stressful to an investor that is short the market, but an upward move will be.

Second, stress-scenarios are chosen using a methodology that is designed to make the financial system robust to a large set of shocks. Two different stress-testing approaches are used to generate robustness.

The first approach, labeled stress-maximization or SM for short, chooses a scenario that maximizes stress to the financial system subject to a plausiblity constraint on the scenario. Specifically, the scenario is chosen to be a worst case for the financial sector among a set of bounded scenarios that may occur with some chosen probability level such as 99 percent. If capital policy makes the financial system resilient against this worst-case scenario, then by construction the financial system will also be resilient to the set of all other scenarios in the 99 percent probability set. The financial sector will hence be robust with a confidence level exceeding 99 percent.

The SM approach is designed to satisfy a sufficient condition for robustness. Its principle advantage is that it orthogonalizes sources of risk, and identifies those sources of risk that create the greatest risk exposures for the financial system. However, because it satisfies a sufficient condition for a robustness, the stress scenario and resulting capital requirement are overly conservative.

The second approach, labeled constrained stress maximization, or CSM for short, simulate many scenarios using monte-carlo analysis and then chooses capital requirements that satisfy a necessary and sufficient condition for achieving robustness with a given degree of confidence. This approach achieves robustness at the lowest possible capital cost, given the portfolio holdings of the banks. ${ }^{8}$ Further capital savings are achieved through setting bank-specific capital requirements that promote better sharing of risks for systemic-risk purposes. The bank-specific requirements are schedules of risk exposure and bank capital changes which keep the level of robustness of the financial system unchanged. Allowing banks to trade along their risk-exposure / capital schedules provides them with the opportunity to save on capital while maintaining financial system robustness. ${ }^{9}$

\footnotetext{
${ }^{8}$ In a related but very different setting Weber and Willison (2011) also choose capital injections in the least costly way to achieve a systemic risk objective.

${ }^{9}$ Other approaches to setting capital for systemic risk are based on banks returns through their return correlations, conditional expected shortfalls, or their CoVaR (see for example Acharya (2010), (2012) and the references therein). A disadvantage of these return-based approaches is that they identify systemically risky banks but don't identify how banks can reduce their systemic risk; i.e. how can two banks reduce their return correlations if they don't know the factors that are driving it. The proposed method, by contrast sets capital charge schedules based on risk-factor exposures. Hence, it identifies the exposures that banks should share differently to reduce capital charges for systemic risk.
} 
Additional capital savings are achieved by releasing information that promotes systemic-riskreducing trades between bank and nonbank financial market participants. Many types of information releases may help to reduce systemic risk. In the current version of this paper, the information that is released is the stress scenario that has the maximum likelihood among the set of worst stress scenarios for which the financial sector is robust. It turns out the factor realizations in this scenario are related to the relative marginal systemic risk reductions that the banking sector can achieve through better sharing of risk with non-bank financial market participants. Thus, the stress-scenario is an advertisement for areas where the gains for systemic risk reduction through risk-sharing between bank and non-bank financial market participants are greatest.

Implementing new approaches to systemic-risk stress-testing require new ways of thinking about how to use and collect supervisory information on banks and financial institutions. In particular, in the new approach, supervisory information on exposures will be used for constructing the scenarios that are used in systemic risk stress tests. Therefore, exposure information should be collected and stored in ways that make it most useful for creating stress scenarios and conducting supervisory stress-tests.

Tailoring stress-tests to achieve robustness with some degree of probabilistic confidence, requires models of the joint probability distribution of the risk factors that affect financial institutions. Therefore, models of the joint distribution of the factors should be further developed and refined for use in systemic-risk stress-testing.

Before proceeding, it is important to identify why banks and markets on their own will fail to hold capital and share risk in a way that provides the socially optimal level of stability (aka robustness), and why properly implemented regulatory stress-testing and capital requirements should be a part of the solution.

The banking and finance literature cites a number of reasons for why banks and markets will not provide the socially optimal amount of financial stability. To cite just a few, these include negative externalities associated with fire sales [Diamond and Rajan (2009), Korinek (2011), ], that too large to fail banks will take excessive risks, and that banks have incentives to fail together because this increases their likelihood of being bailed out together [Acharya (2001), Acharya and Yorulmazer (2007)].

In addition to the above failures, the level of robustness may also be suboptimal because banks have imperfect information about each others' risk exposures and joint returns, and as a result don't hold informationally efficient amounts of excess capital during good times to step-in and replace or absorb distressed intermediaries during bad times. ${ }^{10}$ Regulatory stress-tests and capital

\footnotetext{
${ }^{10}$ Specifically, the returns to acquiring the assets of distressed intermediaries depends on the joint distribution of their asset values, and on the amounts of capital they have set aside to absorb distressed institutions. Because these amounts are not publicly known, and for proprietary reasons cannot be publicly revealed, banks don't hold informationally efficient amounts of excess capital for acquiring distressed firms.
} 
policy, properly implemented can help to improve on this outcome because regulators observe each bank's risk exposure information and therefore have better information on banks joint returns (and distress) than do any banks individually. This information can be used to provide banks with incentives to hold closer to the socially optimal amounts of capital. ${ }^{11}$ This information can also be used to encourage banks to share risks in a way that is more efficient in terms of systemic risk.

The remainder of the paper contains 4 sections. The next section presents the main ideas in the paper. In the context of a one-bank example: it illustrates shortcomings in current stresstesting practices, and new approaches for generating stress tests and setting capital. Section 3 shows how the new approaches can be extended to control systemic risk in the banking system. Section 4 presents stylized examples of the new stress-testing approaches, and capital requirements. In addition, it studies the relationship between risk-sharing arrangements among banks and and systemic risk. A final section concludes.

\section{Choosing a Stressful Scenario}

This section discusses how to use information on banks' risk exposures to construct stress scenarios and set economic capital. Many of the ideas in the paper can be explained within the context of a single bank $i$. For simplicity, that is the approach that will be followed in this section.

The analysis starts from the assumption that banks' portfolio risks can be represented by a potentially very large but common set of risk factors $f$. The risk factors represent innovations in the inputs that the banks use to value their assets and liabilities. Alternatively the risk factors may represent the factors that banks use to model the riskiness of their assets and liabilities as part of their risk management and measurement functions.

$V_{i, 0}$ represents the value of bank $i$ today and $V_{i, T}$ is the value of bank $i$ at date $T$, a future date of interest. The banks' value represents the market value of its assets minus the market value of its liabilities.

To illustrate ideas, a Taylor series expansion is utilized to express changes in $V_{i, T}$ as a function of $f$. It is important to emphasize that most of the results in the paper (with the exception of results on which stress-scenario to release publicly) do not rely on Taylor series.

Using Taylor series, the change in bank $i$ 's value, denoted $\Delta V_{i}\left(=V_{i, t}-V_{i, 0}\right)$ can to first and second order can be approximated as a function of $f_{T}$, the factor realizations at date $T$.

$$
\Delta V^{i}=\approx \mu_{i} T+\delta_{i}^{\prime} f_{T}
$$

\footnotetext{
${ }^{11}$ Acharya (2001) also notes that regulators should use their superior knowledge of the joint distribution of banks portfolios when setting capital requirements for banks.
} 
and,

$$
\Delta V^{i} \approx \mu_{i} T+\delta_{i}^{\prime} f_{T}+.5 f_{T}^{\prime} \Gamma_{i} f_{T}
$$

In the approximations the first term $\mu_{i} T$ represents the change in value of the portfolio that is nonrandom (due to for example holdings of riskfree assets) while the remaining terms are due to $f_{T}$.

To simplify the exposition, the non-random terms will be normalized to 0 . In addition, the analysis in the text will concentrate on the first-order approximation. Analysis for the second order approximation is contained in the appendix.

It is useful to begin by highlighting the main deficiency of the macro-scenario based approach to systemic-risk stress-testing that is used in both the US and Europe. The macro-scenario based approach posits a macro-scenario, and then examines how well each bank performs under the scenario. To do so, a macro scenario is generated, and then its effects are projected onto the set of risk factors that affect the bank, producing a particular realization of $f_{T}$, call it $\tilde{f}_{T}$. The bank is evaluated based on $\delta^{\prime} \tilde{f}_{T}$, the loss due to $\tilde{f}_{T}$. If this creates too large a loss, then the bank is deemed to be undercapitalized; but is viewed as well capitalized otherwise.

The following textbook example [Gibson and Pritsker (2000)] illustrate one of the potential problems with this approach. Consider a bank with, for expositional purposes, a very basic balance sheet. The bank funds itself with equity $=\$ 1$ million, and insured deposits which have value $\$ 4$ million. On the asset side, its portfolio has value $\$ 5$ million, which consists of cash holdings, a short position in one year zero coupon bonds, and a long position in 10 year zeros, as detailed in Table 1 . The current zero coupon yield curve is modeled to be flat at 1 percent.

For the purposes of illustration, in this example, I assume stress-tests are being used with the objective of ensuring that the bank has enough equity capital (currently $=\$ 1$ million) to survive over the next three months with probability exceeding 99 percent. This objective will be achieved by evaluating the bank's capital under the stress scenario, and then requiring the bank to have more capital if it is needed. For illustrative purposes, in the example I assume the value of the bank's liabilities, which consist of insured deposits, are not affected by changes in interest rates.

Given the above objective, how should a stress scenario for the bank be chosen? One method that is often used, labelled the ES approach, chooses stresses that are extreme scenarios where an extreme stressful scenario specifies an extreme move for some variables and then sets other variables to their expected values given the extreme moves. In the yield curve example with two bonds, let $X$ denote the yield change on one bond and let $Y$ denote the yield change for the other. An example of an extreme move corresponds to setting $X$ at its 1 st or 99 th percentile $\left[X \in\left\{X_{1}, X_{99}\right\}\right]$, and then choosing the yield for the other bond, $Y$ so that $Y=E[Y \mid X]$. Depending on which bonds are $Y$ and $X$, this generates four possible extreme stressful scenarios. 
An alternative top-down approach, labelled the PS approach, shifts all risk factors in a class by the same amount; i.e. a parallel shift. In the context of the bond example, the stress scenario in the PS approach would shift both bonds yields by the same amount.

The effects that both approaches to stress-testing have on setting capital requirements, as well as the effect of the SM approach are illustrated in Figure 1.

It is useful to begin with the stress maximization (SM) approach. To illustrate that approach the figure has a parallelogram shaped region that contains 99 percent of the probability mass from the joint distribution of the 1- and 10-year yield changes over a 3-month period. Of the yield changes inside the region the one that generates the largest losses results in a loss of approximately 2.03 million dollars. Because this loss is the maximal loss inside a region that contains $99 \%$ probability, it immediately follows that if the bank was required to hold sufficient economic capital to perform its financial intermediation activities after absorbing the 2.03 million dollars in losses associated with the worst scenario for the bank inside the region, then with probability of at least 99 percent the bank will be able to continue its financial intermediation activities given its risk exposures. Put differently, setting the bank's capital based on this worst-case shock makes the bank robust to a wide-set of shocks that in this case have probability of at least $99 \%$.

It is useful to instead consider what would happen if the bank chose its capital based on the ES and PS approaches. Of the four extreme scenarios, the one that generates the most extreme losses generates a loss of $\$ .85$ million (labeled -.85 in Figure 1) over a 3 month period. The other 3 scenarios generate a loss of $\$ 0.21$ million or gains of $\$ 0.21$ million and $\$ 0.85$ million.

It turns out that the true 99th percentile of the portfolio's losses is about 1.3 million dollars of loss. Therefore, all four extreme scenarios turn out to greatly understate the economic capital that is required. If instead the stress-scenario that is used to set capital charges was based on parallel shifts in the yield curve (the PS approach) then the amount of capital held would also be inadequate. To illustrate, note that the bank's position is hedged against parallel yield curve changes. As a result, parallel yield curve changes, which occur along the blue 45 degree line in the figure generate almost no changes in the value of the bank's portfolio even when the size of the parallel shifts are very large. This means if capital was naively set based on a parallel yield curve shift stress-test, then the amount of capital that was held would be small and would clearly be insufficient to achieve 99 percent confidence.

There are two reasons why the ES and PS approaches to generating stress scenarios and setting capital perform poorly in this example. The first is that they don't choose the correct direction for the stress. This is particularly clear in the case of the PS approach, which only considers shifts of the yield curve in a direction in which the bank is hedged.

The ES approach fails for a similar reason since the stress scenarios it chooses are also not 
too different from a parallel shift. The ES approach fails for another reason: in the ES approach capital is set based on the scenario $X$ and $\mathrm{E}(Y \mid X)$. Choosing stress-scenarios and setting capital in this way fail to consider the variation of $Y$ around its conditional mean as a determinant of how much capital the bank should hold even though this variation should affect capital holdings in most settings.

This analysis shows that for stress-testing in the case of one bank, some of the very simple ways of setting up stress-tests don't require the bank to hold enough capital for its own survival, while the alternative stress maximization approach ensures the bank has sufficient capital to attain robustness against a wide-variety of shocks.

The SM approach succeeds in setting enough capital because it is explicitly designed to do so. The approach is motivated by the idea that the bank should hold enough capital so that it is robust to severe but plausible stress scenarios. This in turn raises the question of what types of plausible stresses is the bank vulnerable to, and for the set of plausible stresses how large are the possible losses against which the bank should hold economic capital.

Plausible scenarios are often modeled under the assumption that the factor vector $f_{T}$ has an elliptical distribution that for simplicity is multivariate normal. ${ }^{12}$

$$
f_{T} \sim \mathcal{N}(0, \Omega)
$$

A scenario is defined to be plausible if the realization of $f_{T}$ in the scenario is not too far out in the tails of a multivariate normal. Formally, a scenario for $f_{T}$ is considered plausible if

$$
\Omega^{-.5} f_{T} \in S
$$

where in the case of two factors

$$
S=\{(x, y) \mid x \in[-a, a] \text { and } y \in[-s, s]\}
$$

For notational purposes I will refer to the set $S$ as a trust set, which represents a set of factor outcomes against which the bank is sufficiently capitalized. The plausibility condition places restrictions on the shape of the trust sets. The plausibility condition can best be understood as restrictions on the transformed risk factors $u=\Omega^{-.5} f_{T}$. The transformation expresses the bank's risk factors $f_{T}$ in terms of a set of independent risk factors $u$ that are distributed $\mathcal{N}(0, I) .{ }^{13}$ The

\footnotetext{
${ }^{12}$ With some additional difficulty the factors could instead be modeled with a fat-tailed distribution such as a multivariate student-t.

${ }^{13}$ The risk factors are independent in this case because they are normally distributed and uncorrelated. If the risk factors are instead multi-variate student- $t$, then the transformed risk factors will be uncorrelated but not independent.
} 
restriction of the independent risk factors to the set $A$ means the realizations of each element of $u$ lie beween $-a, a$; hence each independent risk factor in the system cannot lie too far out in the tail of its marginal distribution, where "too far out" is determined by the choice of $a$ (which then determines the set $S$ ). Because the bank is only being stressed for scenarios in $S$, it is also important that the probability of the set $S$ is large enough to insure that the bank is well capitalized against a large set of plausible scenarios. To ensure that this is the case, $s$ can be chosen so that the probability of the set $S$, given by,

$$
\operatorname{Prob}(S)=[\Phi(s)-\Phi(-s)]^{2}
$$

is sufficiently large. ${ }^{14}$ For example, to ensure that the bank can weather bad scenarios with probability of at least $99 \%, s$ should be chosen so that

$$
[\Phi(s)-\Phi(-s)]^{2}=0.99
$$

and the stress scenario $f_{\min }$ should be chosen so that

$$
f(\min )=\min _{f} \delta^{\prime} f
$$

such that,

$$
\Omega^{-.5} f \in S \text {. }
$$

This minimization problem can be rewritten as:

$$
\begin{aligned}
& \min _{f \mid \Omega^{-.5} f \in S}\left[\delta^{\prime} \Omega^{.5}\right] \times\left[\Omega^{-.5} f\right] \\
= & \min _{u \in S} \delta^{* \prime} u \\
= & \min _{u_{i} \in[-s, s]} \sum_{i} \delta_{i}^{*} \times u_{i}
\end{aligned}
$$

The solution for $u$ and $f$ (denoted $u(\min )$ and $f(\min )$, and the worst linear loss in portfolio value are

$$
\begin{aligned}
u(\min )_{i} & =-a \times \operatorname{sign}\left(\delta_{i}^{*}\right) \quad \text { for all } \mathrm{i} \\
f(\min ) & =\Omega^{\cdot 5} u(\min )
\end{aligned}
$$

Worst Linear Loss $=\delta^{\prime} f(\min )$

\footnotetext{
${ }^{14}$ If $f_{T}$ is multivariate student-t, with covariance matrix $\Omega$, then the elements of $u=\Omega^{-.5} f_{T}$ are not independent. In that case $s$ solves

$$
\int_{-s}^{s} \int_{-s}^{s} g\left(k_{1}, k_{2}\right) d k_{1} d k_{2}=(1-\alpha),
$$

where $g(.,$.$) is the density function of a multivariate student-t.$
} 
For Example 1, the trust set is a box in terms of the transformed variables $u$ (not shown) and is a parallelogram in terms of $f_{T}$. Figure 1 illustrates the boundary of the set of plausible scenarios for $f$. The approximate worst-case linear loss in $A$ is at one of the corners of the parallelogram. Because a first-order approximation is used to find this point, the actual worst case loss over the set $S$ differs from the amount identified, but the difference is small in this case. Using quadratic approximation of the change in portfolio value, with the same trust set $S$ the difference will typically be even smaller. However, when using quadratic approximation of the change in portfolio value, it is computationally convenient to choose a slightly different $99 \%$ trust set (Figure 2). ${ }^{15}$ Whichever 99\% trust set is utilized, if there is no error in approximating changes in portfolio value, then the required capital using both estimates is a conservative estimate of the amount of capital actually needed to achieve robustness with $99 \%$ probability.

Variations on SM type approaches for stress-testing individual banks have been proposed before [Breuer et al (2009), Gonzalez-Rivera (2003), Studer (1997)]. Most variations differ in their choice of trust sets. The usual choice of trust sets with Gaussian risk factors requires the risk factors to satisfy the inequality

$$
f_{T}^{\prime} \Omega^{-1} f_{T} \leq k
$$

where $k$ is chosen so that the set of $f_{T}$ which satisfy the restriction have a known probability such as $99 \%$. A pitfall in using trust sets that are based on a quadratic form is they can produce highly unrealistic stress scenarios in some circumstances. To cite one example, suppose there are 100 risk factors that are distributed $\mathcal{N}\left(0, I_{100}\right)$ with $k=135.81$, and that banks exposures to these factors is $\delta=(1, \epsilon, \epsilon, \ldots, \epsilon)^{\prime}$, where $\epsilon$ is an arbitrarily small number greater than 0 . In the example, $k$ is chosen so that the trust set has probability $99 \%$. Because each element of $\delta$ other than the first is very small, the choice of $f_{T}$ that lies within the trust set and approximately maximizes losses sets the first element of $f_{T}$ to -11.65 and sets its remaining elements to zero. The problem is this choice of $f_{T}$ is totally unrealistic because its first element is so far out into the tails of its marginal distribution. It suggests there is something wrong with the method that is used to define the trust set. In particular, the choice of trust set does not realistically restrict the marginal distribution of the factor realizatons that can be chosen. To overcome this difficultly, the trust sets in this paper restrict a linearly transformed version of $f_{T}$ denoted $u$, to lie within a cube. Because the cube bounds the range of the marginals in each dimension, it avoids the above problem that arises with trust sets based on quadratic forms. Nevertheless, for reasons that are discussed below, the variant of the SM approach that I propose still produces stress scenarios that generate overly conservative capital estimates. As a result other approaches are needed.

The last approach for setting economic capital is the CSM, or constrained stress maximization approach. In the context of a single bank, the CSM approach corresponds to computing the

\footnotetext{
${ }^{15}$ There are two ways to implement the maximization with quadratic approximation. The more difficult method imposes the constraint $\Omega^{-1 / 2} f_{T} \in S$. The more straightforward method imposes the constraint $P^{\prime} \Omega^{-1 / 2} f_{T} \in S$ where $P$ is a rotation matrix that depends on $\Omega$ and $\Gamma$. See the appendix for details.
} 
bank's value at risk for the 99th percentile of its loss distribution. This value is computed by using information about the banks risk exposures and shock distribution. If the bank holds capital against this amount, then it will hold the necessary and sufficient capital to cover its losses and still perform financial intermediation with probability 99 percent. In this sense, it achieves precisely the desired robustness objective, and does so without setting capital on the basis of any single stress scenario.

Before continuing, it is important to summarize the main lessons from this one-bank example.

1. Stress tests need to use information on banks risk exposures in order to ensure that they choose directions of stress that are meaningful.

2. If stress tests are used to set economic capital, then they should appropriately use information on the joint distribution of the risk factors when setting capital.

3. If a goal of stress testing and capital policy is to ensure that banks are robust to other plausible scenarios, then stress tests and capital policies should be explicitly designed to achieve this objective.

The next section applies the insights from designing stress scenarios for a single bank to the problem of designing systemic risk stress tests for the banking system.

\section{A Framework for Systemic-Risk Stress Testing}

The analysis proceeds in four subsections. First systemic risk stress-testing is contrasted with stress-testing for individual banks. Second, the analysis defines systemic risk and financial stability and provides a methodology for measuring them. The third and fourth show how the SM and CSM approaches can be designed to achieve financial stability objectives. Subsection 3 establishes why the SM approach is overly conservative in setting capital. Subsection 4 shows how the CSM approach saves on capital given banks initial risk exposures and how it can be adapted to given banks incentives to better share risk among themselves and with others in order to to reduce capital costs while achieving systemic risk objectives.

\subsection{Systemic-Risk Stress Tests vs Stress Tests for Individual Banks}

The purpose of systemic risk stress tests is to ensure that the banking and other parts of the financial system are sufficiently capitalized as a whole to support normal levels of financial intermediation activity. In this respect, the purpose of systemic risk stress-tests is different from individual bank capital requirements. 
Individual bank capital requirements are designed to prevent the insolvency of individual banks by for example requiring them to hold enough capital to survive for a year with probability exceeding 99.9 percent. However, even if a bank holds enough capital to survive for a year, if it is solvent but becomes poorly capitalized, it may be unable to lend for a while. If other lenders are financially healthy enough to step in and lend to that banks borrowers, it may not represent a problem for the financial system. But, if many lenders are solvent but become poorly capitalized at the same time, it could create problems since there may not be enough healthy lenders to step in and provide financial intermediation. The purpose of systemic risk stress tests and associated capital injection policy is to reduce the likelihood of an in impairment to financial intermediation.

\subsection{Systemic Risk and Financial Stability: Definitions and Measurement}

For the purposes of this paper, systemic risk is defined by the probability (or probability distribution) of impairment of financial intermediation capacity in the economy. The precise form for how intermediation capacity should be modeled is beyond the scope of this paper. For simplicity, the measures of financial capacity impairment and systemic risk that are used in this paper are based on three basic assumptions:

1. Each financial institution $i$ 's maximal intermediation capacity is proportional to the assets on its balance sheet, and the constant of proportionality is the same across all financial institutions. ${ }^{16}$

$$
\text { Intermediation Capacity }[i]=\alpha A_{i}
$$

2. Each institution $i$ 's impairment in capacity to performing financial intermediation is the product of its maximal intermediation capacity, and a function $D_{i}\left[C_{i}\right]$ which represents its level of financial distress. $D_{i}\left[C_{i}\right]$ takes values in $[0,1]$ and is a function of bank $i$ 's capital ratio.

3. When the percentage of intermediation capacity in the country that becomes impaired exceeds a threshold $\theta$, then financial intermediation in the economy becomes impaired, creating systemic problems.

It is important to stress that these assumptions could be replaced by others. The only element of these assumptions that are essential is that intermediation capacity should be tied to variables that are regulated (such as bank capital) so policy can be used to improve this capacity, and intermediation capacity should be linked to fundamentals, as it will be below.

\footnotetext{
${ }^{16}$ Note: the constant of proportionality could be greater than 1 if institutions create and securitizes a large number of loans.
} 
The assumptions suggest that a systemic risk measure at time horizon $T$ should be based on the percentage of banking assets that are held by banks in distress at $T$. This amount is denoted by $S A D_{T}$, which stands for System Assets in Distress at $T$ :

$$
\begin{aligned}
S A D_{T} & =\frac{\sum_{i} \alpha A_{i} \times D_{i}}{\sum_{i} \alpha A_{i}} \\
& =\frac{\sum_{i} A_{i} \times D_{i}}{\sum_{i} A_{i}}
\end{aligned}
$$

$S A D_{T}$ should in general depend on banks capital and on the economic state at date $T$, which is represented by the vector of risk-factor realizations $f_{T} \cdot{ }^{17}$ To simplify notation, the dependence of $S A D_{T}$ on $f_{T}$ will typically be suppressed.

Building on the dam analogy and robustness concepts discussed in section 2, systemic risk can be defined in terms of the probability that $S A D_{T}$ exceeds $\theta$. Specifically,

Definition 1 A financial system is defined to be weakly alpha-theta stable (written as $\alpha-\theta$ stable hereafter) over the time horizon $[0, T]$ if

$$
\operatorname{Prob}_{0}\left(S A D_{T} \geq \theta\right) \leq \alpha
$$

As an example of the definition, if $T$ is one year, $\theta$ is 10 percent, and $\alpha$ is one percent, then weak $\alpha-\theta$ stability at horizon $T$ means the probability conditional on information today (time 0 ) that banks representing 10 percent or more financial assets will be in financial distress a year from today is less than 1 percent.

Weak $\alpha-\theta$ stability is a measure of financial stability since it reveals information about the probability that the financial system will achieve a particular stablity goal $\theta$. For a given level of $\theta, \alpha$ is a measure of systemic risk because it measures the likelihood that the stability goal will not be met, and that financial impairment will occur. Although it is not pursued here, measures of systemic risk that are analogous to expected shortfall could based on the expected amount of impairment when impairment exceeds $\theta$. In addition, weak $\alpha-\theta$ stability objectives and expected shortfall objectives can both be used in regulating banks activities, and/or setting capital. ${ }^{18}$

The CSM approach sets capital to satisfy a necessary and sufficient conditions for weak $\alpha-\theta$ stability. The SM approach satisfies a stronger concept, which I refer to as $\alpha-\theta$ stability:

\footnotetext{
${ }^{17}$ The should also depend on the network of banks connections through interbank markets, but this is abstracted away from for now.

${ }^{18}$ It may be possible for banks to game regulations based on the probability that SAD exceeds a threshold by effectively writing deep out of the money options on SAD. Such options can satisfy the probability constraint yet load up on systemic risk. Supplementing regulations on the probability that SAD exceeds a threshold with regulations on expected shortfall should help to prevent such gaming.
} 
Definition 2 Let $f_{T}$ be the vector of risk-factor realizations that affect the value of financial firms at time $T$. The financial system is $\alpha-\theta$ stable at horizon $T$ if there is a set of possible factor realizations $F_{T}$ such that

$$
\operatorname{Prob}_{0}\left(\left\{f_{T}\right\} \mid f_{T} \in F_{T}\right)=1-\alpha
$$

and for all $f_{T} \in F_{T}, S A D_{T}\left(f_{T}\right) \leq \theta$.

The definition of $\alpha-\theta$ stability implies that for all realizations of $f_{T}$ within a set $F_{T}$ that has probability $1-\alpha$, the amount of system assets in distress is less than or equal to $\theta$. An immediate implication is that the set of $f_{T}$ for which $S A D_{T}>\theta$ has probability which is less than or equal to $\alpha$. Therefore, $\alpha-\theta$ stability implies weak $\alpha-\theta$ stability.

The definitions of systemic risk and financial stability rely on a measure of financial distress. Bank $i$ is defined to be in financial distress if its economic capital ratio at date $T, C_{i, T}$, falls below some threshold $c_{i}^{*}$ that in theory should depend on economic conditions and bank $i$ 's characteristics such as its portfolio, and lines of business. ${ }^{19} C_{i, T}$, bank $i$ 's capital ratio is approximated using a "policy-augmented" first or second order Taylor series expansion in the risk factors $f$ that affect the bank's value. The second order expansion has form

$$
C_{i, T} \approx C_{i, 0}+C I_{i, 0}+\delta_{i}^{\prime} f_{T}+\frac{1}{2} f_{T}^{\prime} \Gamma_{i} f_{T}
$$

In the expansion $C_{i, 0}$ is $i$ 's capital ratio at date $0, C I_{i, 0}$ is any crease in capital ratios that is required just after date 0 due to regulatory policy. It is important to remember that $C_{i, T}$ is expressed in ratios. Therefore, if bank $i$ has to increase its capital ratio by $C I_{i, 0}$ just after date 0 , then the amount of capital it must somehow raise is $A_{i} \times C I_{i, 0}$. Similarly, $\delta_{i}$ and $\Gamma_{i}$ are the sensitivities of bank $i$ 's capital ratio to the risk factors $f_{T}$; this is different than earlier in the paper where $\delta$ and $\Gamma$ measured sensivity of the bank's equity value to the risk factors.

Using the definition of distress, the event of bank $i$ 's financial distress at date $T$ can be denoted by the indicator function $d_{i, T}$ where

$$
d_{i, T}= \begin{cases}1 & C_{i, T}<C_{i}^{*} \\ 0 & C_{i, T} \geq C_{i}^{*}\end{cases}
$$

While it is convenient to define financial distress as occurring when a bank's capital ratio is less than some threshold, banks that are slightly above or below the threshold are probably experiencing

\footnotetext{
${ }^{19}$ Bank $i$ 's capital ratio at date $t$ is defined as $C_{i, t}=\left(A_{i, t}-L_{i, t}\right) / A_{i, t}$ where $A_{i, t}$ and $L_{i, t}$ denote the value of bank $i$ 's assets and liabilities at time $t$.
} 
about the same amounts of financial distress. Therefore it makes more sense to model financial distress as a continuous function of a bank's capital ratio. To do so, the binary distress function $d_{i, T}$ is replaced with the continuous distress function $D_{i, T}$. To ensure $D_{i, t}$ takes values between 0 and 1 , it is chosen to be a cumulative distribution function (CDF) whose arguments are the bank's capital ratio, capital ratio parameters, and some tuning parameters. For simplicity, $D_{i, T}$ below uses the logistical function CDF; the standard Gaussian CDF produces qualitatively similar results. The logistical distress function is given by:

$$
D_{i, T}=\frac{1}{1+e^{-a_{i}-k_{i}\left(C_{i}^{*}-C_{i, T}\right)}} .
$$

It approaches 1 as $C_{i, T}$ becomes small and approaches 0 as $C_{i, T}$ becomes large. The parameters $a_{i}$ and $k_{i}$ are tuning parameters that can be dependent on the characteristics of bank $i$ and provide flexibility in modeling. Specifically, $a_{i}$ determines the level of bank $i$ 's distress when $C_{i, T}=C_{i}^{*}$, and $k_{i}$ determines the rate at which bank $i$ 's distress changes when $C_{i, T}$ moves away from $C_{i}^{*}$.

The measure of system assets in distress used in this paper comes from equation 6 with the assets measured as of time 0, while using the distress function from equation 7 .

$$
S A D_{T}\left(C I, f_{T}\right)=\frac{\sum_{i} A_{i, 0} D_{i, T}}{\sum_{i} A_{i, 0}}
$$

Note that in the left-hand side of the equation, the notation for $S A D_{T}()$ makes explicit that it is a function of the $N \times 1$ capital injection vector $C I$, and the risk factors $f_{T}$.

With this definition, it is becomes relatively straightforward to conduct stress tests and set capital using the SM and CSM approaches.

\subsection{The SM approach}

Let $A$ denote the $N \times 1$ vector of banks total asset holding. With this notation, the capital injection vector $C I^{M}$ and the stress-scenario $f_{T}^{M}$ are the solutions to the min-max problem:

$$
\begin{aligned}
C I^{M}=\operatorname{argmin}_{C I} A^{\prime} C I, \quad \text { such that } \\
f_{T}^{M}=\operatorname{argmax}_{f_{T} \in F_{T}} S A D_{T}\left(C I^{M}, f_{T}\right), \\
\operatorname{Prob}_{0}\left(\left\{f_{T}\right\} \in F_{T}\right)=1-\alpha \\
\operatorname{SAD}_{T}\left(C I^{M}, f_{T}^{M}\right) \leq \theta .
\end{aligned}
$$


In words, the $S M$ approach finds the minimal amount of capital to inject to ensure that for stress scenario $f_{T}^{M}$, which is the factor realization in $F_{T}$ that maximizes system assets in distress, the resulting system assets in distress is less than $\theta$. By construction, this approach achieves $\alpha-\theta$ stability.

The main drawback of SM approach is that it is very conservative. To provide intuition for its conservatism, note that if $C I^{M}$ has been chosen optimally, then based on a second order approximation of $S A D_{T}($.$) , the problem of finding f_{T}^{M}$ reduces to the maximization problem:

$$
\begin{aligned}
f_{T}^{M} & =\max _{f_{T}} \delta(S A D)^{\prime} f_{T}+.5 f_{T}^{\prime} \Gamma(S A D) f_{T} \quad \text { such that } \\
\Omega^{-.5} f_{T} & \in S
\end{aligned}
$$

where $S$ is a set of factors with probability $1-\alpha$, and $\delta(S A D)$ and $\Gamma(S A D)$ are the first and second order derivatives of $S A D_{T}\left(C I, f_{T}\right)$ with respect to $f_{T}$ evaluated at $f_{T}=0$.

The random variables $u=\Omega^{-.5} f_{T}$, is a vector of independent standard normal random variables. The appendix shows that after transforming the maximization problem in terms of $u$, and choosing the trust set $S$ conveniently the problem becomes:

$$
u_{T}^{M}=\max _{u \in S} \delta^{* \prime} u+.5 u^{\prime} \Gamma^{*} u
$$

where $\delta^{*}$ is a vector, and $\Gamma^{*}$ is a diagonal matrix, $K$ is the number of risk factors, and $S$ is a box in $K$-space that has edges $[-s, s]$. Choosing the trust-set $S$ as a box rules out very extreme elements of the support of the marginal distribution of each element of $u$; this treatment avoids the very extreme worst-case scenarios that can be chosen when the trust set is quadratic.

After the transformation, the problem of finding the stress scenario that maximizes $S A D_{T}$ over the set $S$ reduces to solving $K$ separate quadratic maximization problems that each involve choosing the realization of an independent random variable. For example, the $k^{\prime}$ th maximization, solves for the k'th element of $u$, denoted $u_{T}(k)$, that solves:

$$
u_{T}(k)=\max _{u[k] \in[-s, s]} \delta^{*}[k] u[k]+.5 u[k]^{2} \Gamma^{*}[k, k]
$$

where the notation $x[i]$ or $x[i, j]$ represents the corresponding elements of the matrix $x$.

Put differently, this means after transformation the banking system can be viewed as a set of quadratic exposures to bets on $k$ independent sources of risk. The worst outcome for $S A D_{T}$, the outcome chosen by the SM approach, is that all $K$ independent bets simultaneously experience 
outcomes that generate maximal distress for the financial system. This is highly implausible. For example, if there are 500 independent bets, and each is akin to a coin flip, then the probability that all go bad simultaneously is absurdly low $\left(=.5^{500}=3 \times 10^{-151}\right)$. Because the $S M$ approach requires that capital is held against this very low probability event, it is extremely conserative in high dimensions, and is too conservative to use as a basis for setting capital. ${ }^{20}$ Nevertheless, by identifying worst stresses for the banking system as a whole in every independent risk direction, the approach is useful for highlighting risk vulnerabilities. For example, the losses from each of the independent $u_{k}[m]$ factors can be computed; those which generate the largest gains in SAD can be identified, and the exposures to these factors can be traced back to individual banks. Thus, the SM method is likely to provide useful information for risk-monitoring, even if it does not provide a reasonable stress scenario for setting capital because it is too conservative.

Before turning to the next stress-testing methodology, it is important to mention the relationship of this work to an alternative methodology for choosing stress-scenarios that is known as reverse stress-testing. Reverse stress tests and new variants of it (Glasserman et. al. (2012)) find stress scenarios that are the most likely to generate losses of a given size. Because reverse stress tests focus on relatively likely scenarios, they help identify relatively plausible loss scenarios that firms may want to plan against. In addition, as will be illustrated below, such maximum likelihood scenarios contain information that is potentially useful for risk-sharing. It is important to emphasize, however, that reverse stress-testing is a complement but not a substitute for the SM or CSM approaches because the latter approaches when combined with capital policy, are designed to achieve robustness of the financial system while reverve stress testing on its own is not. ${ }^{21}$.

\subsection{The CSM approach}

The goal of the the CSM approach is to set capital injections that provide a given level of systemic stability, and then to facilitate the creation of markets for reducing required capital through the improvement of risksharing.

\footnotetext{
${ }^{20}$ A part of the "conservatism" stems from the multivariate normality assumption, which is tantamount to assuming there are $K$ independent risk-factors. In a setting where instead the risk-factors have a multivariate student-t distribution, then all of the risk factor realizations are dependent. Nevertheless, based on similar reasoning, the SM approach is still overly conservative. To see why, do a first order expansion of $S A D_{T}$ in terms of $f_{T}$. Because a multivariate student-t with $J$ degrees of freedom is the ratio of a multivariate normal with an independent chi-squared $J$ random variable, after suitable transformation the bets can be expressed as bets on the ratio of independent normals divided by the same chi-squared $J$ random variable. In this setting the worst case scenario will still involve each normal random variable moving in the wrong direction given the exposure. This will still be highly implausible.

${ }^{21}$ To illustrate why reverse stress-testing may not achieve robustness of $S A D$, note that in a setting with two banks, the most likely stress-scenario for which $S A D=L$ might involve the first bank experiecing large losses, and the second bank experiencing small losses. The second most likely scenario might involve the first bank experiencing small losses and the second bank experiencing large losses. The cheapest way to hold capital against the most likely scenario is to inject capital into the first bank, but this will not provide protection against the second most likely scenario. If the second most likely scenario has high enough probability then the financial system will not be robust just based on holding capital against the most likely scenario.
} 
The CSM approach for setting capital solves the minimization problem:

$$
C I^{C S M}=\operatorname{argmin}_{C I} C I^{\prime} A
$$

such that

$$
\operatorname{Prob}_{0}\left(S A D_{T}\left(C I^{C S M}, \tilde{f}_{T}\right) \geq \theta\right) \leq \alpha
$$

The CSM approach solves for the minimum amount of capital that needs to be injected into the financial system to satisfy the "robustness constraint" in equation 18; in addition it solves for which banks capital ratios should be increased or decreased to attain weak $\alpha-\theta$ stability given banks current risk exposures.

The complicated part of the optimization is modeling the robustness constraint. To do so, I use monte carlo simulation methods to nonparameterically estimate the probability density function of $S A D_{T}$, as a function of parameters that include banks risk exposures to the factors $\left(\delta_{k}\right.$ and $\Gamma_{k}$ $k=1, \ldots K$.), and the $K \times 1$ vector of capital injections (in ratio form) $C I$. An important advantage of this nonparametric approach is that it is not necessary to make restrictive assumptions about the joint distribution of the risk factors $f_{T}$; i.e. $f_{T}$ can be high dimensional, have fat-tails, stochastic volatility, etc., and most of the methods for setting capital and sharing risk can still accomodate it. $^{22}$ The details on the estimation are in the appendix. To economize on notation, most of the parameters will be suppressed until needed. The nonparametric density estimate that $S A D_{T}=u$ is denoted by the function $\hat{g}(u \mid C I)$. Because $S A D_{T}$ was created so that $0 \leq S A D_{T} \leq 1$, integrating this density function from $\theta$ to 1 produces an estimate of the probability that $S A D_{T}$ will exceed $\theta$, denoted $G(\theta, C I)$ :

$$
\hat{G}(\theta, C I)=\int_{\theta}^{1} \hat{g}(u \mid C I) d u
$$

The function $\hat{G}($.$) is a differentiable function of its parameters. This is very useful in solving$ for the optimal capital injections $C I$ given banks initial positions, and for doing the comparative statics.

The CSM approach has four components. The first is a set of required capital injections $C I^{*}$ that achieve weak $\alpha-\theta$ stability in the least costly way given banks initial risk exposures. These are found by estimating the function $\hat{G}($.$) and then numerically solving for C I^{*}$ using standard methods. After expressing the minimization problem as an equivalent maximization problem, the FOCs for the optimal choice of $C I^{*}$ are just the FOCs of the standard Langrangean maximization problem. In the maximization, I have used the notation $C C I(C I, \lambda)$ to represent the lagrangean

\footnotetext{
${ }^{22}$ The exception is the results on risk-sharing between banks and nonbanks. The results for that part of the paper relies on elliptical distributions.
} 
function because at the optimized values of $C I$ and $\lambda, C C I$ is equal to the cash capital that is injected into the banking system.

$$
C C I(C I, \lambda)=\max _{C I, \lambda}-C I^{\prime} A+\lambda[\alpha-\hat{G}(\theta, C I)]
$$

To simplify the exposition, I will assume all of the constraints are binding. Under this assumption, $C I^{*}$ and $\lambda$ satisfy the FOCs

$$
\begin{aligned}
C C I_{C I}: & 0=-A-\lambda \hat{G}_{C I}\left(\theta, C I^{*}\right) \\
C C I_{\lambda}: & 0=\alpha-\hat{G}\left(\theta, C I^{*}\right)
\end{aligned}
$$

The second component of the CSM approach is a schedule of cash-capital charges which delineate after the capital injection $C I^{*}$ how much additional equity capital in total must be held by the banking system when a bank alters its risk exposures. For example, if bank $j$ altered the $\delta$ component of its risk exposure by an amount $d \delta_{j}$, then by the envelope theorem, $d C C I$ the minimum amount of additional capital that needs to be injected into the banking system to maintain robustness is given by:

$$
d C C I=-\lambda\left[\hat{G}_{\delta_{j}}\left(\theta, C I^{*}\right)\right]^{\prime} d \delta_{j}
$$

where $\hat{G}_{\delta_{j}}$ is a vector that represents the vector of partial derivatives of $\hat{G}$ with respect to the elements of $\delta_{j}$. This means (for small position changes) if each bank $j$ faced a capital charge that required it to raise $\lambda \hat{G}_{\delta_{j}}\left(\theta, C I^{*}\right)$ dollars of equity per unit of change in its $\delta$ risk exposures, it would internalize the effects of its position changes on the robustness of the financial system. It is important to emphasize that $d C C I$ measures the amount of equity capital that needs to be injected into the banking system due to a change in bank $j$ 's risk exposures, but it does not specify who should hold the capital.

When bank $j$ changes its exposure by an amount $d \delta_{j}$, each bank $i$ should alter its equity capital by an amount $A_{i} \frac{\partial C I_{i}}{\partial \delta_{j}} d \delta_{j}$. This leads to the third component of the CSM approach, the change in all banks capital ratios that are required because of the changes in risk exposures of each bank $j$. Working through the comparative statics shows that when a bank alters its risk exposures, all banks could in theory alter their capital injections in response. The formula for $d C I$ comes from straightforward comparative statics and is given by:

$$
d C I=-\lambda^{-1} \hat{G}_{C I, C I}^{-1} \hat{G}_{C I} d \lambda-\lambda^{-1} \hat{G}_{C I, C I}^{-1} \hat{G}_{C I, \delta_{j}} d \delta_{j},
$$


where

$$
d \lambda=\frac{\lambda \hat{G}_{\delta_{j}}-\hat{G}_{C I}^{\prime} \hat{G}_{C I, C I}^{-1} \hat{G}_{C I, \delta_{j}}}{\hat{G}_{C I}^{\prime} \hat{G}_{C I, C I}^{-1} \hat{G}_{C I}} d \delta_{j}
$$

The comparative static expressions for $d C C I$ and $d C I$ are valid if the function $G($.$) is twice dif-$ ferentiable in the parameters $\delta, \Gamma, C I$, which is standard. The nonstandard part of the comparative statics is that they rely on a nonparametric estimate. Since $\hat{G}($.$) is estimated nonparametrically,$ the comparative statics also require that $\hat{G}($.$) and its first two partial derivatives converge to G($. and its first two partial derivatives as the number of monte-carlo draws of $f$ become large. These requirements may restrict the kernel functions and bandwidth choices that can be used for the nonparametric density estimate, but the precise form of these restrictions have not yet been incorporated in the paper or the empirical analysis that follows. ${ }^{23}$

The fourth, and final component of the CSM approach is the release of public information on some of the scenarios that are used in the stress-test. Recalling that many scenarios are used in the stress-test, this raises the question of what types of information should be released publicly? Here, I propose releasing information that facilitates risk sharing between banks and non-bank financial market participants that are not systemically important. The purpose of facilitating risk-sharing of this type is that it provides a means of transferring risk away from systemically important banks, which helps reduce the capital that they would be required to hold against systemic risk. To help create a market for transferring the risk, it is useful to provide information on the marginal benefits in terms of capital savings that the banking sector would receive by sharing risk.

To derive the information that should be released I make the following assumption:

Assumption 1 After $C I^{*}$ has been chosen optimally $S A D_{T}$ is approximately linear in $f_{T}$ and has form

$$
S A D_{T}=\beta_{0}+f_{T}^{\prime} \beta_{1}
$$

where $\beta_{1}$ and $f_{T}$ are $N \times 1$ and $f_{T}$ is distributed elliptically $(0, \Omega)$.

Under this assumption the benefit in terms of cash capital that is saved by the banking sector by altering $\beta_{1}$ by the amount $d \beta_{1}$ is as follows:

\section{Lemma 1 Under assumption 1}

$$
\frac{d C C I}{d \beta_{1}} \propto \Omega \beta_{1}
$$

\footnotetext{
${ }^{23}$ See Chacon et. al. (2010) and the references therein.
} 
Proof: Under assumption 1 and equation 23, $\operatorname{Prob}\left(S A D_{T} \geq \theta\right)=G(\theta, C C I)=\operatorname{Prob}\left(\frac{\beta_{1}^{\prime} f_{T}}{\sqrt{\beta_{1}^{\prime} \Omega \beta_{1}}}>\frac{\theta-\beta_{0}}{\sqrt{\beta_{1}^{\prime} \Omega \beta_{1}}}\right)$. Because $f_{T}$ is elliptical with mean 0 , the last expression $=1-\psi\left(\frac{\theta-\beta_{0}}{\sqrt{\beta_{1}^{\prime} \Omega \beta_{1}}}\right)$ where $\psi($.$) is the CDF$ of an elliptical random variable that has mean 0 and variance 1 . Therefore from equation 23 , differentiation of $1-\psi($.$) shows \frac{d C C I}{d \beta_{1}}=\lambda G_{\beta_{1}}=\lambda \psi^{\prime}\left(\frac{\theta-\beta_{0}}{\sqrt{\beta_{1}^{\prime} \Omega \beta_{1}}}\right) \times\left(\frac{\theta-\beta_{0}}{\left(\beta_{1}^{\prime} \Omega \beta_{1}\right)^{3 / 2}}\right) \times \Omega \beta_{1} \propto \Omega \beta_{1}$.

The results of this lemma are fairly intuitive: under the assumptions, $\Omega \beta_{1}$ is the vector of each factor's covariance with $S A D_{T}$. It is intuitive that the larger is this covariance the greater is the benefit in terms of capital that the banking system can save by sharing this risk with others (provided they are not systemic). The challenge is how should $\Omega \beta_{1}$ be computed given that $\beta_{1}$ is not known. A possible solution comes from the monte-carlo simulation. It turns out the amount of cash capital that is saved is related to the maximimum likelihood stress-scenario for which $S A D_{T}=\theta$, as shown in the following lemma.

Lemma 2 Under assumption 1, the maximum likelihood stress scenario $f_{T}^{M L}$ for which $S A D_{T}=\theta$, is given by $f_{T}^{M L} \propto \Omega \beta_{1}$.

Proof: When the distribution function is elliptical, the likelihood function of $f_{T}$ has form $\uparrow\left(f_{T}\right)=$ $C h\left(f_{T}^{\prime} \Omega^{-1} f_{T}\right)$, where $C$ is a scalar and $h$ is a function that is nonzero on its domain. The FOC for solving for the value of $f_{T}$ that maximizes the log-likelihood function and for which $S A D_{T}=\theta$ is $\frac{h^{\prime}\left(f_{T}^{\prime} \Omega^{-1} f_{T}\right)}{h\left(f_{T}^{\prime} \Omega^{-1} f_{T}\right)} \times 2 \Omega^{-1} f_{T}=\mu \beta_{1}$, where $\mu$ is the lagrange multiplier of the constraint. Algebra then shows that $f_{T}^{M L} \propto \Omega \beta_{1}$.

The implications for information provision on stress-scenarios are given in the following proposition:

Proposition 1 Under assumption 1, releasing the maximum likelihood stress-scenario for which $S A D_{T}=\theta$ will provide the market with information on the relative marginal benefits in terms of relaxing capital requirements that the financial sector gains by selling its factor risks to the private sector.

Proof: Obvious from the lemmas.

The proposition shows that under the conditions in assumption 1, a reverse stress-test that chooses the maximum likelihood stress scenario for a given amount of loss (see Glasserman et al (2012) ) has an interpretation in terms of the relative benefits of reducing risks from different types of factors. It thus provides a new way of interpreting some stress scenarios. To provide an example, suppose there are two risk factors, percentage changes in GDP and percentage changes in the value of the S \& P 500. If the percentage change in GDP in the maximimum likelihood stress-scenario 
that causes $S A D_{T}=\theta$ is $-4 \%$ and the percentage change in the $\mathrm{S} \& \mathrm{P} 500$ is $-2 \%$, the stress scenario would indicate that the marginal benefit in terms of systemic risk capital savings from reducing the banking systems exposure to percentage changes in GDP is twice as large as the benefit from reducing its exposure to percentage changes in the stock market.

The reason the information provided by $f_{T}^{M L}$ is novel and valuable is that up to a constant of proportionality it provides information on $\Omega$ and $\beta_{1}$. Because the latter depends on all banks risk exposures, $\beta_{1}$ is not known to any individual bank or to market participants individually or collectively. Thus, without the stress scenario, the marginal benefits of sharing different types of risks with nonbanks for systemic risk purposes may be unknown to banks and market participants alike.

When implementing the CSM approach, there are two ways to attempt to solve for $f_{T}^{M L}$. The first is examine all of the monte-carlo scenarios for which $\left|S A D_{T}-\theta\right|$ is small and choose the value with the highest likelihood. The second is numerically solve for $f_{T}^{M L}$.

A version of the results in Proposition 1 generalize to the case when $f$ is elliptical but has mean of $\mu$ not equal to 0 . The result is provided in proposition 2 in Section $\mathrm{C}$ of the appendix.

To close this section, it is useful to summarize and discuss how the elements of the CSM approach would ideally function together. The first step of the approach solves for the minimum cost capital injections to achieve systemic risk objectives given banks current portfolios. Although not made explicit above, this maximization allows for capital payouts provided that systemic risk objectives are satisfied. The second step of the approach solves for schedules of cash-capital charges that banks would have to pay for altering their portfolio exposures. To implement this approach, each bank $j$ would have to raise $d C C I_{j}$ of cash from equity holders and initially contribute it to a national systemic risk fund. Each banks contribution to the fund would internalize the contributions to systemic risk from altering its portfolio contributions. Because banks will face different schedules based on the contributions of their different positions to systemic risk, the schedules will create a basis for trade that will allow the banks to save on contributions to the national systemic risk fund by trading with each other. In addition, because of the public release of information (step 4) about the maximum likelihood stress scenario, banks will also have the opportunity to share risks with systemically important nonbanks. This will further alter their contributions to the national systemic risk fund. Finally, the revenues that are contained in the systemic risk fund are disbursed to banks according to the formulas in step 2. The disbursement of capital to banks in this step ensures the capital in the systemic risk fund is disbursed to provide robustness in the least expensive way possible. 


\section{An Example of Stress-Tests and Capital Injections for Systemic Risk.}

This section contains a very preliminary and uncalibrated analysis of the CSM approach when risk-sharing can only take place among the banks. It's performance is studied under four economic settings. In all four settings, there are 6 banks that have identical distress functions. The banks differ in terms of the size of their assets, with $A_{i}=i$ for $i=1,2, \ldots 6$. The banks assets cause the banks to have exposures to two risk factors $f_{1}$ and $f_{2}$ that for simplicity are each $\mathcal{N}(0,1)$ and independently distributed. Recall that the banks distress is a function of their capital ratios (measured by equity to assets). In the first setting, labeled "perfect" risk-sharing, I assume there is "perfect" risk-sharing, which means the sensitivity of each banks capital ratio to the factors is the same, and is normalized to 1 . Note that the perfect risk-sharing scheme does not necessarily correspond to the optimal robust risk-sharing scheme for systemic risk, because the robust objective function is concerned with minimizing joint distress while under "perfect" risk-sharing, the banks distress functions are perfectly correlated, which means they all fail together. All other settings begin from perfect risk-sharing factor sensitivities, and then solve for optimal risk-sharing and capital injections among the banks. The second and third settings, labeled shorting and no-shorting, solve for optimal risk-sharing and capital injections when banks are and are not allowed to take long or short positions in the individual factors resectively. ${ }^{24}$ In the fourth setting, optimal capital injections are solved for when the banks begin from perfect risk-sharing, and then banks 5 and 6 alter their risk-sharing of factor 1, by bank 5 going increasing long in factor 1 while bank 2 goes increasingly short.

In all four settings, optimal capital injections and risk-sharing are chosen to maximize the objective in equation 17 subject to the robustness contstraint 18 . The distress functions is parameterized as described in appendix B, and the robustness constraint is approximated using monte-carlo simulation and non-parametric density estimation as described appendix D. In all simulations $\theta=.10$ and $\alpha=0.05$.

Three results emerge from the preliminary analysis. The first is that in some circumstances, in particular cases 1 - 3, the amounts of capital that need to held in total are very similar (Table 2) even though the portfolio holdings that support those capital choices can be very different. In particular, when there is "perfect" risk sharing, all banks capital ratios have an exposure of 1 to each factor; when shorting is allowed, the bank portfolios that require the minimum amount of capital for systemic risk require that all banks hold the same relative portfolio weights, which means all banks are essentially exposed to the same single factor. However, some banks have long exposures to the factor while others have short exposures (Table 3). This makes intuitive sense since if the banks hold positive and negative exposures to the same risks, this can help to reduce the likelihood

\footnotetext{
${ }^{24}$ When banks take short positions in the factors this can be interpreted as taking a short position in a futures market, or as buying protection against movements in the factor from another bank.
} 
that banks will experience distress at the same time since if some banks are experiencing distress others must be doing well. ${ }^{25}$

When banks are not allowed to take short positions, the risk-sharing arrangement that minimized capital injections while satisfying the robustness constraint involved "narrow banking." In this configuration, some banks have positive exposures to the factors and hold capital, while others hold capital, but have no exposure to the factors. In this case, the banks that are holding capital have no factor risk, but are holding it as reserves to provide financial intermediation if the larger banks that hold the factors experience distress. It is important to keep in mind that in this example although some banks sell their factor exposures, all banks are financial intermediaries that make loans. What is "narrow" is how the risks from the factors are shared. The systemic risk objective function favors the risk being concentrated among a few well capitalized banks, while other banks are well capitalized but do not hold this risk (Table 4 ).

The second interesting, but perhaps not surprising result is that when the robustness constraint only minimizes the likelihood that systemic assets in distress exceed some threshold level, then such a restriction generates many different distributions of systemic assets in distress, all of which satisfy the robustness constraint (Figure 3 ). This is true despite the fact that the distributions of system assets in distress beyond the threshold $\theta$ as measured by expected shortfall are very similar (Table 2 ). The variation in the distributions of $S A D$ across the different risk-sharing arrangements (perfect, short, no-short) suggest that if the levels of $S A D$ affect welfare even when $S A D<\theta$, then this should be taken into account when designing capital standards.

The third result is that although across the three very different risk-sharing arrangments considered above require the same amounts of economic capital, deviations from these risk-sharing arrangements do generate large increases in capital. To illustrate, I consider the fourth setting, when banks 5 and 6 alter their exposures to factor 1 . This increases the total amount of capital that needs to be injected into the financial system (Figure 4); it alters the amounts of capital that banks 5 and 6 have to hold (Figure 5). Because the CSM approach solves for the least expensive way to to inject capital into banks to achieve robustness, the change in risk-sharing between banks 5 and 6 should and does alter the amount of capital that banks $1-4$ hold, in this case reducing it (Figure 6).

The differences in risk based capital that need to be held to ensure robustness as risk-sharing arrangements change show there is scope for tailoring capital charges to encourage sharing of risk that preserves robustness while saving on capital.

\footnotetext{
${ }^{25}$ This result slighty refines Wagner (2010). Wagner argues against diversified portfolios because it leads to similarity of risk taking and is bad for systemic risk. In the example above, by contrast, all banks take positions in the same portfolio; they are all diversified; but it is good for systemic risk because some banks are long or short the portfolio and therefoe will not fail together.
} 


\section{Conclusion}

Stress-testing bank portfolios is a relatively old idea, but the application of stress testing techniques to systemic risk mitigation is still in its infancy. This paper has critiqued systemic-risk stresstesting practice as applied in the US. The current U.S. stress-testing and recapitalization policy, by focusing on stress-tests that use one or a small number of severe stress scenarios, is likely to produce a financial system that achieves some level of robustness to other less severe scenarios. However, it is not clear how much robustness is achieved against the wider of set shocks that could affect the banking system because achieving robustness is not formally a part of the stress-test design.

This paper has provided a framework for formally modeling the process of systemic risk stresstesting. Using the framework, the paper analyzed current U.S. stress testing practice. Three main results emerged from the analysis. First, to achieve a desired degree of robustness it is necessary to use exposure information and the distribution of risk factors when determining how much capital should be injected. Second, the "stress-testing" and capital injection methodology that achieves a necessary and sufficient condition for robustness is estimated by using many scenarios in a montecarlo analysis that is applied to the banking system. This suggests there may be room to improve upon capital setting methodologies that are based on one or a small number of stress scenarios. Third, improvements to risk sharing can substitute for capital in achieving systemic risk reduction. This paper shows that in some settings the maximum likelihood stress scenario for which robustness constraints on capital are just binding is proportional to the marginal capital saved when the banking sector shares risks with non-bank market participants. This suggests, that some stressscenarios may have a role in promoting risk sharing to save on capital, even though reliance on single stress scenarios is not optimal for setting capital.

The final contribution of providing a formal stress-testing framework with well defined objectives, is that the framework helps to highlight areas where the stress-testing methodology requires further development and analysis. In the case of the framework above, the linkage between capital ratios and finanicial intermediation capacity should be further refined so that the framework can be calibrated and operationalized. In addition, it should be extended to multiple periods, account for banks linkages through counterparty credit risk, including interbank markets. These extensions remain a topic for future research.

\section{References}

Acharya, V., 2001, "A Theory of Systemic Risk and Design of Prudential Bank Regulation," Journal of Financial Stability 5, 224-255. 
Acharya, V., Pedersen, L.H., Philippon, T., and M. Richardson, (2010) "Measuring Systemic Risk," Mimeo, NYU Stern School of Business.

Acharya, V., Pederson, L.H., Philippon, T., and M. Richardson (2012), "How to Calculate Systemic Risk Surcharges," in Quantifying Systemic Risk.

Acharya, V. V., and T. Yorulmazer, 2007, "TooMany to Fail: An Analysis of Time-inconsistency in Bank Closure Policies," Journal of Financial Intermediation 16: 1 - 31.

Alessandri, P., Gai, P., Kapadia, S., Mora, N., and C. Puhr, (2009), "Towards a Framework for Quantifying Systemic Stability," International Journal of Central Banking, September, 47-81.

Alfaro, R., and M. Drehmann, 2009, "Macro Stress-Tests and Crises: What have we Learned," BIS Quarterly Review, December, 29 - 41.

Board of Governors of the Federal Reserve System (2009a), "The Supervisory Capital Assessment Program: Design and Implementation."

Board of Governors of the Federal Reserve System (2009b), "The Supervisory Capital Assessment Program: Overview of the Results."

Borio, Claudio, and Mathias Drehmann (2009), "Towards an Operational Framework for Financial Stability: "Fuzzy" Measurement and its Consequences," BIS Working Paper No. 284.

Boss, M., Breuer, T., Elsinger, H., Krenn, G., Lehar, A., Puhr, C., and M. Summer, 2006, "Systemic Risk Monitor: Risk Assessment and Stress Testing for the Austrian Banking System," Mimeo.

Breuer, T., Jandacka, M., Rheinberger, K., and M. Summer, (2009), "How to Find Plausible, Severe, and Useful Stress Scenarios," International Journal of Central Banking 5, no. 3., 205-224.

Carlson, Mark, Shan, H., and M. Warusawitharana (2011), "Capital Ratios and Bank Lending: A Matched Bank Approach," Working Paper, Board of Governors of the Federal Reserve System.

Chacón, J.E., Duong, T., and M.P. Wand, 2010, "Asymptotics for general multivariate kernel density derivative estimators," Mimeo.

Diamond, Douglas W., and Raghuram G. Rajan (2011), "Fear of Fire Sales and the Credit Freeze," Quarterly Journal of Economics, forthcoming.

Gibson, M.S., and M. Pritsker, 2000, "Improving Grid-Based Methods for Estimating Value at Risk of Fixed Income Portfolios," The Journal of Risk, 3 (Winter 2000/2001): 65-89.

Glasserman, P., Kang, C., and Kang, W., 2012, "Stress Scenario Selection by Empirical Likelihood," Mimeo.

Gonzalez-Rivera, G., 2003, "Value in Stress: A Coherent Approach to Stress-Testing", Journal of Fixed Income 13(2), 7 - 18. 
Greenlaw, D., Kashyap, A.K., Schoenholtz, K. and H.S. Shin, (2012) "Stressed Out: Macroprudential Priciples for Stress Testing," Chicago Booth Research Paper No. 12-08.

Hanson, S. G., Kashyap, A.K., and J.C. Stein, "A Macroprudential Approach to Financial Regulation," Journal of Economic Perspectives, 25, no. 1. 3-28.

Hirtle, Beverly, Til Shuermann, and Kevin Stiroh (2009), "Macroprudential Supervision of Financial Institutions: Lessons from the SCAP," Federal Reserve Bank of New York Staff Report No. 409.

Huang, X., Zhou, H., and Zhu, H., 2009, "A Framework for assessing the systemic risk of major financial institutions," Journal of Banking and Finance 33, 2036-2049.

Korinek, A., 2011, "Systemic Risk-Taking: Amplification Effects, Externalities, and Regulatory Responses," ECB Working Paper 1345.

Mishkin, Frederick S., (1999) "Global Financial Stability: Framework, Events, Issues," Journal of Economic Perspectives, 13 (Fall), pp. 3-20.

Peristiani, Stavros, Morgan, Donald P., and Vanessa Savino, (2010) "The Information Value of the Stress Test and Bank Opacity," Federal Reserve Bank of New York Staff Report 460, July.

Rosengren, Eric S. (2011), "Defining Financial Stability and Some Policy Implications of Applying the Definition," Keynote Remarks at the Stanford Finance Forum, Graduate School of Business, Stanford University.

Shleifer, Andrei, and Robert W. Vishny (2010), "Unstable Banking," Journal of Financial Economics, 97 (3), pp. 306-318.

Shleifer, Andrei, and Robert W. Vishny (2011), "Fire Sales in Finance and Macroeconomics," Journal of Economic Perspectives, 25 (1), pp. 29-48.

Studer, G., and H.J. Luthi (1997), "Quadratic Maximum Loss," in VAR: Understanding and Applying Value-at-Risk, Risk Publications, London, pp. 307-311.

Wagner, W., 2010, "Diversification at financial institutions and systemic crises," Journal of Financial Intermediation 19, 373-386.

Webber, L., and M. Willison, 2011, "Systemic Capital Requirements," Bank of England Working Paper 436, October.

\section{Appendix}




\section{A Quadratic Minimization}

The quadratic approximation of the change in value of an individual firm is given by:

$$
\Delta V \approx \delta^{\prime} f+.5 f^{\prime} \Gamma f
$$

where

$$
f \sim \mathcal{N}(0, \Omega)
$$

After the change in variable,

$$
u=\Omega^{-.5} f,
$$

the change in value can be written as

$$
\Delta V \approx \delta^{\prime} \Omega^{5} u+.5 u^{\prime} \Omega^{\cdot 5} \Gamma \Omega^{.5} u
$$

where $u \sim \mathcal{N}(0, I)$.

Because $\Omega^{.5} \Gamma \Omega^{5}$ is symmetric, it has representation

$$
\Omega^{.5} \Gamma \Omega^{.5}=P D P^{\prime}
$$

where $D$ is a real diagonal matrix and $P$ is a matrix of orthonormal eigenvectors.

Applying the change of variables $x=P^{\prime} u$ then tranforms $\Delta V$ to

$$
\begin{aligned}
\Delta V & \approx \delta^{\prime} \Omega^{\cdot 5} P x+.5 x^{\prime} D x \\
& \approx \tilde{\delta} x+.5 x^{\prime} D x
\end{aligned}
$$

where $x \sim \mathcal{N}(0, I)$.

To solve find the worst case stress-scenario over over a set of $f$ that has probability $1-\alpha$, we solve

$$
\Delta v_{\min }=\min _{x} \tilde{\delta}^{\prime} x+.5 x^{\prime} D x
$$


such that

$$
x_{i} \in[-a, a] \text { for all i., }
$$

and

$$
[\Phi(a)-\Phi(-a)]^{N}=(1-\alpha)
$$

Specifying the constraints on $x$ in this way guarantees that mapping from $x$ to $A$, the set of possible $f$ realizations has probability $1-\alpha$.

The reason for doing a change of variables to $x$ is that the minimization problem has the very simple form

$$
\min _{x_{i} \in[-a, a]} \sum_{i} \tilde{\delta}_{i} x_{i}+.5 x_{i}^{2} D_{i i}
$$

which is just $N$ trivial constrainted quadratic minimizations. Denote the solution for $x$ as $x_{\min }$.

After the minimum has been found, transforming back produces

$$
f_{\min }=\Omega^{.5} P x_{\min }
$$

\section{B Choosing Parameters of the Distress Function}

Recall the distress function for bank $i$ has form:

$$
D_{i, T}=\frac{1}{1+e^{-a_{i}-b_{i}\left(C_{i}^{*}-C_{i, T}\right)}}
$$

where $C_{i, T}$, firm $i$ 's capital ratio at time $T$ is modeled as

$$
C_{i, T}=C_{0}+C I_{i}+\delta_{i}^{\prime} f+.5 f^{\prime} \Gamma_{i} f
$$

and $\delta_{i}$ and $\Gamma_{i}$ are first and second-order risk exposure sensitivities for bank $i$.

The parameters of the distress function are $a_{i}, b_{i}$ and $C_{i}^{*}$. A full analysis of how to estimate or calibrate the distress function parameters is beyond the scope of this paper, but one approach is to assume $i$ 's distress function is related to $i$ 's credit risk at time $T$. In the simplest case, $i$ 's distress function at time $T$ is equal to its probability of default between times $T$ and $\tau(\tau>T)$. This 
default probabity is denoted $1-P S(T, \tau)$ where $P S(T, \tau)$ is the probability that bank $i$ survives until time $\tau$ conditional on its capital at time $T$ :

$$
D_{i, T}=1-P S(T, \tau) .
$$

Under this formulation, the log odds of survival between times $T$ and $\tau$ is related to bank i's capital ratio via the formula ${ }^{26}$ :

$$
\log (\text { Survival Odds })(T, \tau)=-a_{i}-b_{i}\left(C_{i}^{*}-C_{i, T}\right)
$$

From this equation, if data on survival odds (or EDFs), and banks capital ratios are available, then under suitable restrictions the parameters of the distress function may be identifiable. ${ }^{27}$

To illustrate this papers framework for modeling systemic risk, instead of choosing a single set of parameters for the distress function, several sets of parameters will be reported. Our baseline configuration assumes that when $c_{i, T}=C_{i}^{*}$, distress $=0.9$, which restricts $a_{i}=2.1972$. To choose $b_{i}$ and $c_{i}^{*}$, I for now set them to 0.45 and 0 . In future revisions assume that to conduct financial intermediation, the banks probability of becoming insolvent over the next year must be less than $\mathrm{p} \%$. In a framework with Gaussian (mean 0) factors and linear exposures, this requires $c_{i}^{*}=$ $-\sqrt{\delta_{i}^{\prime} \Omega \delta_{i}} \Phi^{-1}(p)$. I will apply this formula even when the factors and exposures are not Gaussian. ${ }^{28}$

\section{Generalizing Proposition 1}

Proposition 2 Under the assumptions of 1 , when $f_{T}$ is distributed elliptically $(\mu, \Omega)$, releasing the maximum likelihood stress-scenario for which $S A D_{T}=\theta$ will provide the market with information on the relative marginal benefits in terms of relaxing capital requirements that the financial sector gains by altering its exposure to the stochastic (demeaned) components of $f_{T}$.

\footnotetext{
${ }^{26}$ The odds of survival is the probability of survival between $T$ and $\tau$ divided by the probability of default between $T$ and $\tau$.

${ }^{27}$ Under ideal conditions, $-a_{i}-b_{i} C_{i}^{*}$ and $b_{i}$ are identifiable via OLS. The parameter $C_{i}^{*}$ is not separately identified, but separate identification of this parameter is not needed to compute or simulate distress if the survival function has the form in equation 31. Under more realistic conditions, identification will need to account for the endogeneity of $C_{i, T}$.

In the equation, the scalar $b_{i}$ can alternatively be interpreted as a parametric function $b_{i}($.$) which depends on$ $C_{i}^{*}-C_{i, T}$ and other parameters. For example in similarity with structural models of default $b_{i}()$ could be a function of $\frac{C_{i}^{*}-C_{i, T}}{\sigma_{C} \sqrt{\tau-T}}$, i.e. the distance of capital ratio from some threshold that is normalized by the standard deviation of the capital ratio between times $\tau$ and $T$.

${ }^{28}$ This treatment is similar to requiring that capital is based on risk weighted assets, but it allows for "portfolio effects" in which the capital requirement for an asset depends on the other risks in the portfolio. This is not possible when the capital requirement is set based on risk-weighted assets.
} 
Proof: When the distribution function is elliptical with mean $\mu$, the likelihood function of $f_{T}$ has form $\mathcal{L}\left(f_{T}\right)=C h\left[\left(f_{T}-\mu\right)^{\prime} \Omega^{-1}\left(f_{T}-\mu\right)\right]$, where $C$ is a scalar and $h$ is a function that is nonzero on its domain. The FOC for solving for the value of $f_{T}$ that maximizes the log-likelihood function and for which $S A D_{T}=\theta$ is $\frac{h^{\prime}\left(f_{T}^{\prime} \Omega^{-1} f_{T}\right)}{h\left(f_{T}^{\prime} \Omega^{-1} f_{T}\right)} \times 2 \Omega^{-1}\left(f_{T}-\mu\right)=\pi \beta_{1}$, where $\pi$ is the lagrange multiplier of the constraint. Algebra then shows that $\left(f_{T}^{M L}-\mu\right) \propto \Omega \beta_{1}$. Therefore, knowledge of $f_{T}^{M L}$ and $\mu$ is equivalent to knowledge of a random vector that is proportional to $\Omega \beta_{1}$.

Next, suppose that the banking sector increased its exposure to the random variable $f-\mu$, the demeaned version of $f$ by an amount $d \eta$, evaluated at $\eta=0$. By the envelope theorem, at the optimized value of $C I^{*}, \frac{d C C I}{d \eta}=\left.\lambda G_{\eta}()\right|_{.\eta=0}$, where $G()=.\operatorname{Prob}\left[\beta_{0}+\beta_{1}^{\prime} f_{T}+\eta^{\prime}\left(f_{T}-\mu\right)>\theta\right]=$ $\operatorname{Prob}\left[\frac{\left(\beta_{1}+\eta\right)^{\prime} f_{T}}{\sqrt{\left(\beta_{1}+\eta\right)^{\prime} \Omega\left(\beta_{1}+\eta\right)}}>\frac{\theta-\beta_{0}-\beta_{1}^{\prime} \mu}{\sqrt{\left(\beta_{1}+\eta\right)^{\prime} \Omega\left(\beta_{1}+\eta\right)}}\right]=1-\psi\left[\frac{\theta-\beta_{0}-\beta_{1}^{\prime} \mu}{\sqrt{\left(\beta_{1}+\eta\right)^{\prime} \Omega\left(\beta_{1}+\eta\right)}}\right]$, where $\psi($.$) is the CDF of an$ elliptical random variable with mean 0 and unit dispersion matrix. Differentiating the CDF with respect to $\eta$ evaluated at $\eta=0$ shows $\frac{d C C I}{d \eta} \propto \Omega \beta_{1}$.

Assuming $G($.$) is differentiable in \eta,-\frac{d C C I}{d \eta}$ is the change in cash capital that is saved by transferring risks from banks to systemically unimportant non-banks. Therefore using information on the maximum likelihood stress scenario for which the robustness constraint just binds is equivalent to solving for the relative value of banks reducing their demeaned exposures to the risk factors.

\section{Modeling the Robustness Constraint}

The robustness constraint in the maximization is computed by combining simulation with nonparametric estimation in three simple steps:

1. Makes $\mathrm{N}$ (a large number) i.i.d. draws of $f_{T}$, from its distribution conditional on date 0 . Denote these draws $f_{1}, \ldots, f_{N}$.

Note: there is not a need for this distribution to be Gaussian. It can be almost anything.

2. Using the monte-carlo draws of $f$, estimate the density function of $S A D_{T}$, nonparametrically using kernel density estimation ${ }^{29}$. This density function is denoted $\hat{g}(u ; \delta, C I)$, which represents the probability that the density of $S A D_{T}=u$ conditional on risk exposures $\delta$ and capital injections $C I$.

$$
\hat{g}(u ; \delta, C I)=\widehat{\operatorname{Prob}}\left(S A D_{T}=u\right)=\frac{1}{N h} \sum_{i=1}^{N} K\left(\frac{u-S A D_{t}\left(\delta, C, f_{i}\right)}{h}\right),
$$

\footnotetext{
${ }^{29}$ Values with hats over them are estimated.
} 
where $h$ is the kernel bandwidth. ${ }^{30}$

3. Integrate the nonparametric density to estimate $G^{C}(\theta,$.$) , the probability that S A D_{T}$ is greater than $\theta$ :

$$
\hat{G}^{C}(\theta ; C I, \delta)=\int_{\theta}^{1} \hat{g}(u ; C I, \delta) d u
$$

The robustness constraint requires

$$
\hat{G}^{C}(\theta ; C I, \delta)-\alpha \leq 0 \text {. }
$$

The advantage of estimating the robustness constraint nonparameterically is that $\hat{G}^{C}$ is a smooth function of risk exposures and capital injections. This greatly facilitates optimizing capital and risk-sharing with respect to these parameters.

\footnotetext{
${ }^{30}$ For simplicity, following Silverman's rule, $h$ was chosen as $h=N^{-.2} \times 1.06 \sigma\left(S A D_{T}\right)$, where $\sigma\left(S A D_{T}\right)$ is the sample standard deviation of $S A D_{T}$ in the simulations. The kernel density estimation was computed using a gaussian kernel.
} 
Table 1: Assets for Textbook Example

$\begin{array}{ccc}\text { Asset } & \text { Yield } & \text { Amount Invested } \\ \text { Cash } & 0 & 95 \text { million } \\ 1 \text { Yr ZCB } & 1 \% & -100 \text { million } \\ 10 \text { Yr ZCB } & 1 \% & 10 \text { million }\end{array}$

Notes: For the example in section 2, the Table provides information on the banks asset portfolio, which consists of positions in cash, and one- and ten- year zero coupon bonds (ZCB). 
Table 2: Capital injections and expected shortfall as a function of risk-sharing arrangements

$\begin{array}{cccc} & \text { "Perfect" Risk Sharing } & \text { No Shorting } & \text { Shorting } \\ \text { Capital Injection } & 253.42 & 253.35 & 253.30 \\ \text { Expected Shortfall } & .0065 & .0067 & .0068\end{array}$

Notes: For the example in section 4, the table presents the optimal capital injections into the banking system, and expected shortfall for system assets in distress when the banks in the example engage in "perfect" risk-sharing, when they share risk but cannot short assets, and when they can short assets. 
Table 3: Optimal Factor Exposures for Systemic Risk when Short Positions in the Factors are allowed

$\begin{array}{cccc}\text { Bank } & \text { Assets } & \text { Factor } 1 & \text { Factor } 2 \\ 1 & 1 & -3.23 & -3.21 \\ 2 & 2 & -.22 & -.21 \\ 3 & 3 & -.14 & -.13 \\ 4 & 4 & 1.67 & 1.67 \\ 5 & 5 & 1.69 & 1.69 \\ 6 & 6 & 1.66 & 1.65\end{array}$

Notes: For the example in section 4, the table presents the optimal risk factor exposures as a fraction of assets that minimize capital injections when the banks can take long and short risk exposures. 
Table 4: Optimal Factor Exposures and Capital for Systemic Risk when Short Positions in the Factors are not allowed

$\begin{array}{ccccc}\text { Bank } & \text { Assets } & \text { Factor 1 } & \text { Factor 2 } & \text { Capital } \\ 1 & 1 & 0 & 0 & 9.7667 \\ 2 & 2 & 0 & 0 & 9.7667 \\ 3 & 3 & 0 & 0 & 9.7667 \\ 4 & 4 & 0 & 0 & 9.7667 \\ 5 & 5 & 1.91 & 1.91 & 14.1564 \\ 6 & 6 & 1.91 & 1.91 & 14.1564\end{array}$

Notes: For the example in section 4, the table presents the optimal risk factor exposures (as a fraction of assets) and capital injections that minimize total capital injections when the banks can take long but not short risk exposures. 
Figure 1: Setting Capital Based on Stress Scenarios: An Example Using Interest-Rate Shocks

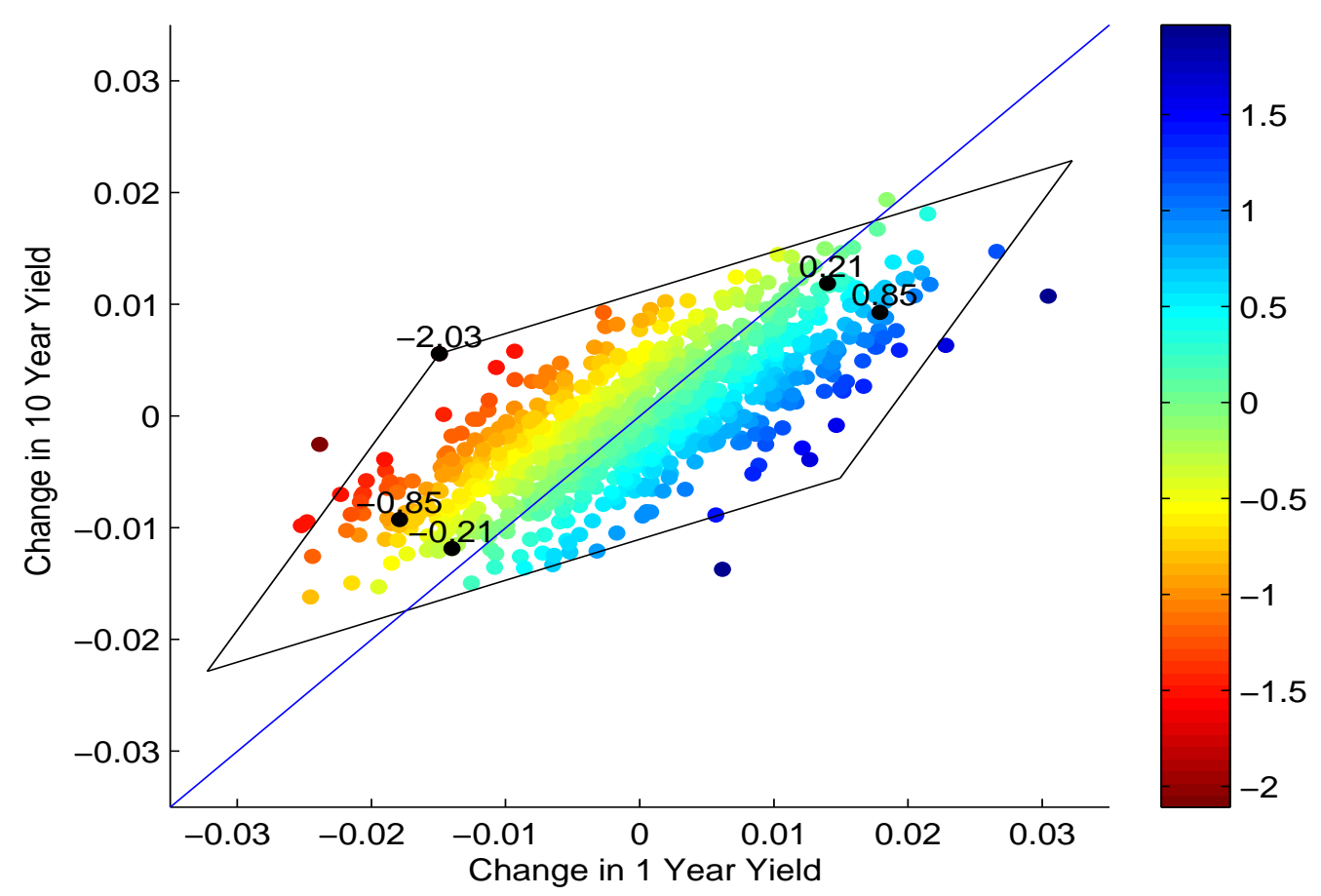

Notes: For the stylized bank whose balance sheet is described in Table 1, the figure presents a plot of changes in portfolio value that can occur for a set of ten-year and one-year yield changes. The figure is used to examine the efficacy of setting capital by using stress-scenarios. Scenarios are generated three ways. First, a scenario is generated through the stress maximization (SM) approach by finding yield shocks that generate the worst portfolio loss for shocks that lie within a parallelogram that contains $99 \%$ of the probability mass of shocks (loss $=-2.03$ million). Second, 4 extreme scenarios are generated that shock one yield up or down by two standard deviations, and the other by its expected change conditional on the first shock (losses $=-.85,-.21$; gains $=.85, .21$ ). Third, scenarios are generated through parallel shifts to the yield curve, which corresponds to movements along the blue 45 degree line in the figure.

The true 99th percentile of loss for the portfolio is a loss of 1.3 million dollars. Therefore, if capital is set based on the first alternative, it will be more than sufficient to cover this loss. If capital is set instead based on the second alternative (extreme scenarios) or the third alternative (parallel yield curve shifts), then the capital holdings will be inadequate to absorb up to 99th percentile of the loss distribution of the bank's portfolio. 
Figure 2: Linear and Quadratric 99\% Trust Sets

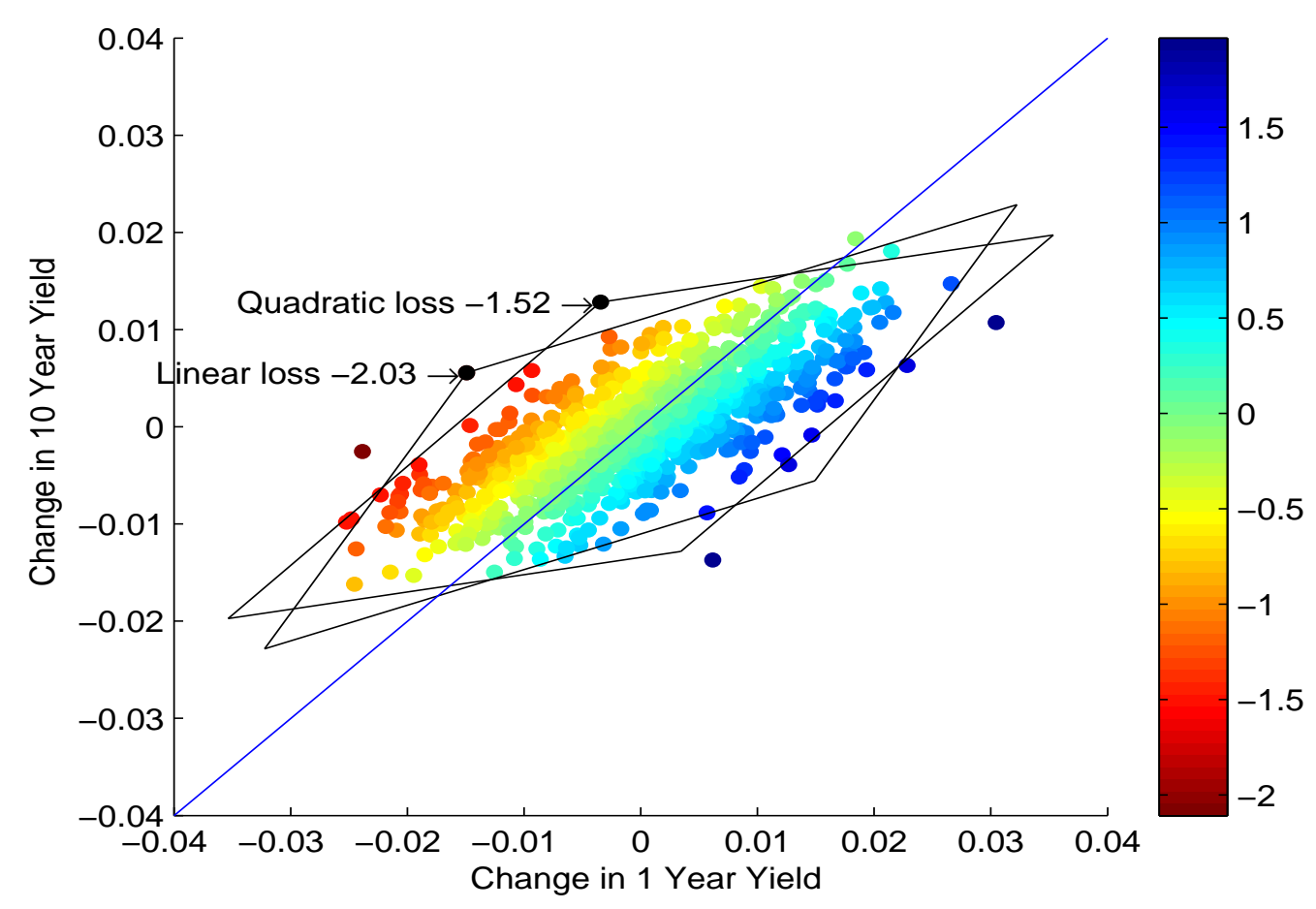

Notes: For the stylized bank in Figure 1, the figure shows the 99\% trust set that was used in Figure 1 , as well as an alternative trust set that is more convenient to maximize over when the bank's value is approximated using a quadratic function of the risk factors. For both trust sets, the worst case loss over the trust set is presented in the figure. Both worst case losses exceed the true 99th percentile of loss. Therefore, setting capital for this bank using the maximal loss criterion and either trust set would result in adequate economic capital for the example considered. 
Figure 3: Distribution of System Assets in Distress for Different Risk Sharing Arrangements

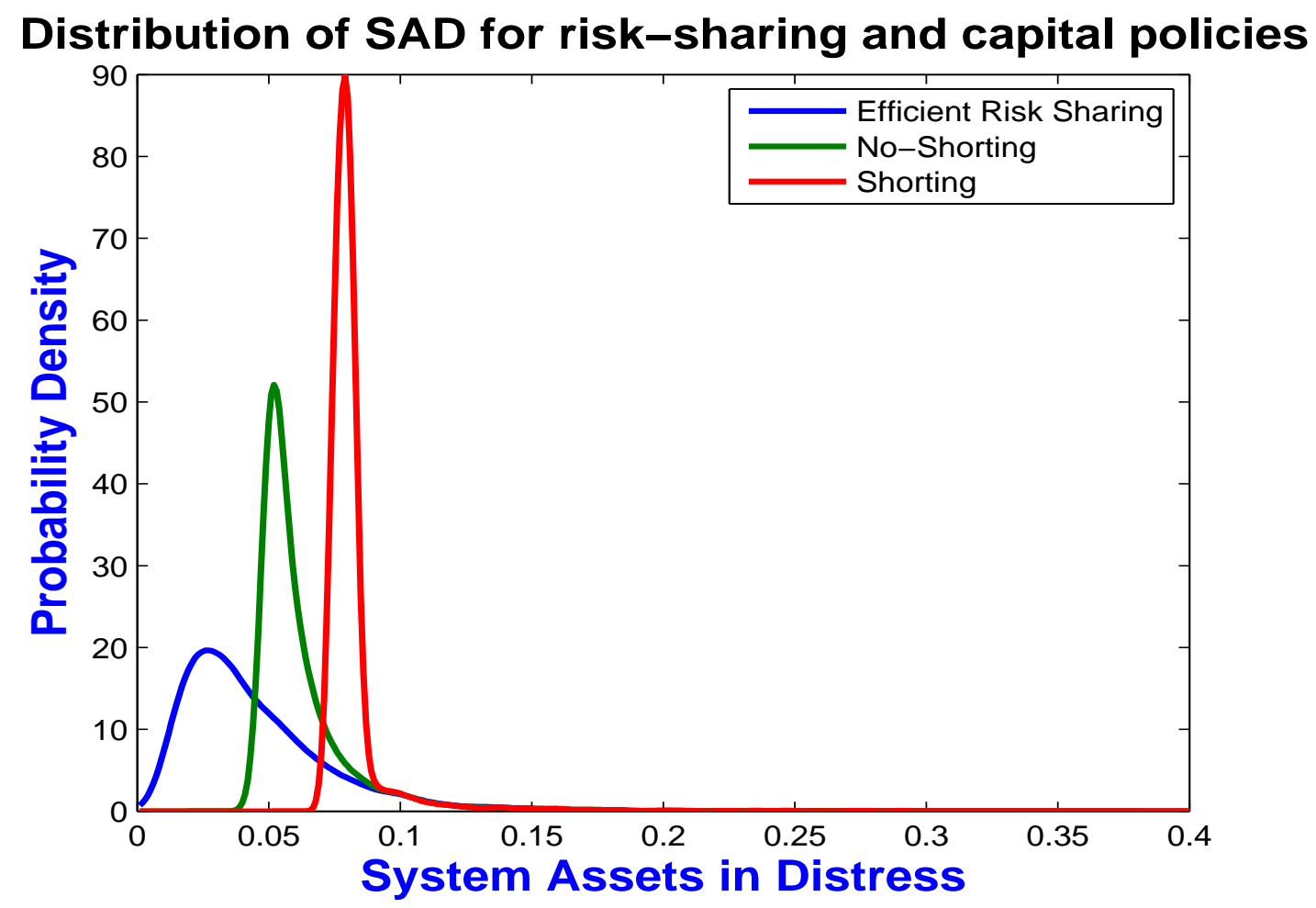

Notes: For the example in section 4, the figure presents the distribution of system assets in distress when the smallest capital injection possible is chosen to satisfy robustness constraints, and when the risksharing arrangement is optimized subject to the resriction that it is "perfect" risksharing, allows for risk-sharing with shorting, or allows risk-sharing but no shorting. 
Figure 4: Capital Required for Deviation from "Perfect Risk Sharing"

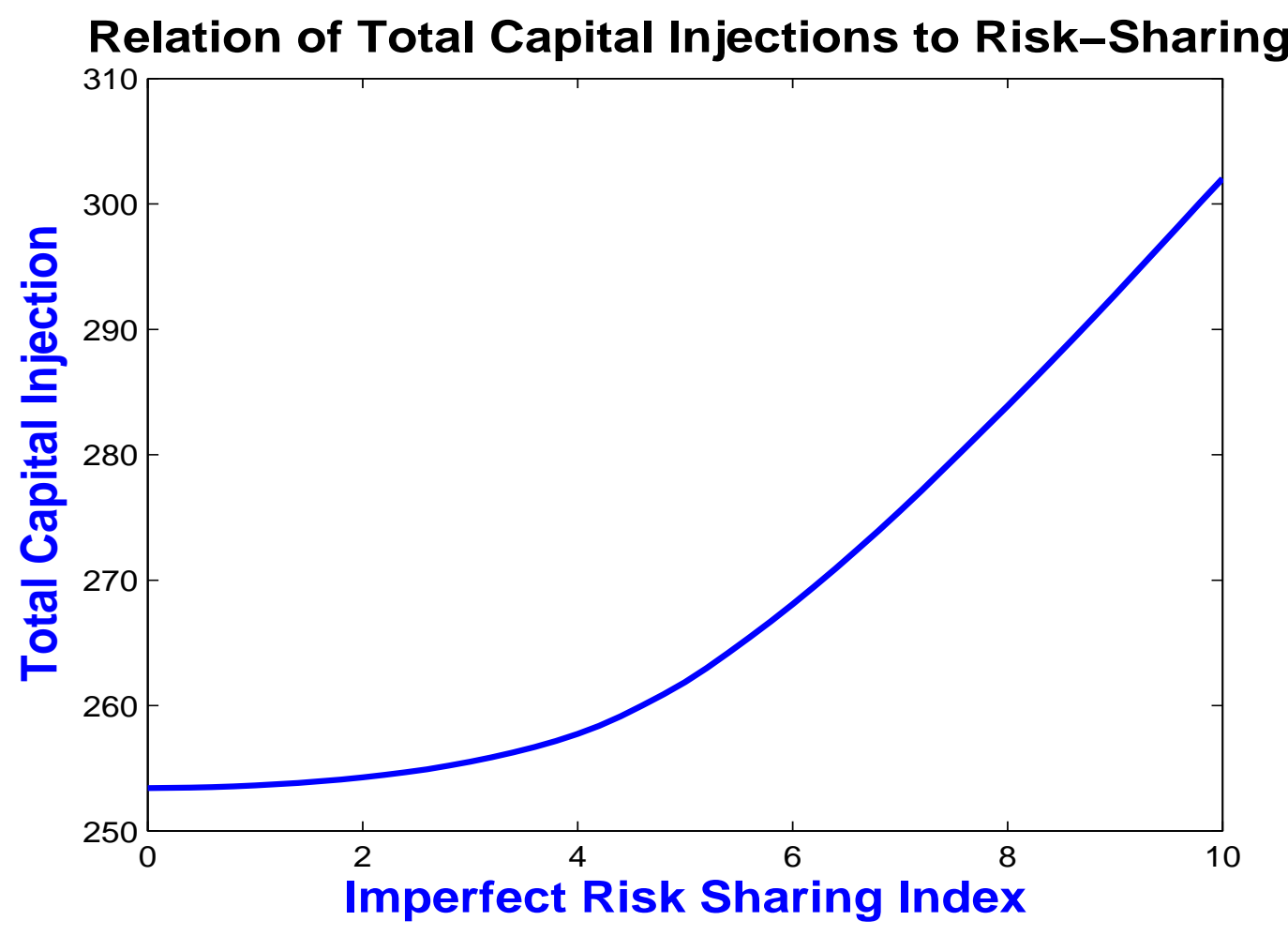

Notes: For the example in section 4, the figure presents the amount of capital that all banks have to hold as a function of the deviation from perfect risk sharing (the imperfect risk-sharing index) for banks 5 and 6 . The imperfect risksharing index runs from 0 to 10 . When it is 0 , the holdings of asset 1 are consistent with perfect risk sharing in which each banks exposure as a ratio of assets is equal to 1 . When the index is 10 , the ratio of exposure to assets for bank 5 is 5 . 
Figure 5: Capital Required for Banks 5 and 6 for Deviation from "Perfect Risk Sharing"

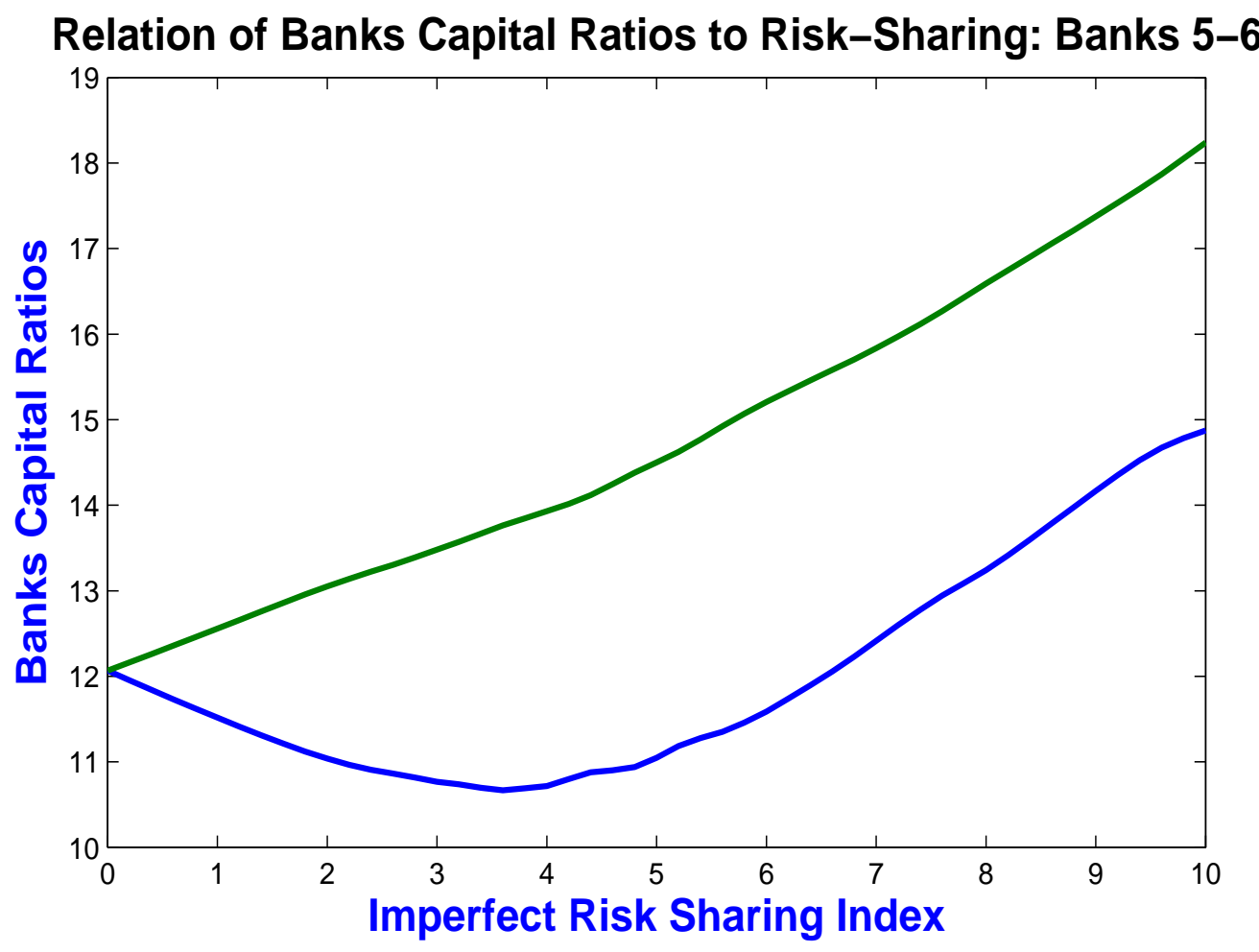

Notes: For the example in section 4, the figure presents the amount of capital that banks 5 and 6 have to hold as a function of the deviation from perfect risk sharing (the imperfect risk-sharing index) for banks 5 and 6 . The imperfect risksharing index runs from 0 to 10 . When it is 0 , the holdings of asset 1 are consistent with perfect risk sharing in which each banks exposure as a ratio of assets is equal to 1 . When the index is 10 , the ratio of exposure to assets for bank 5 is 5 . 
Figure 6: Capital Required for Banks 1 - 4 for Deviation from "Perfect Risk Sharing"

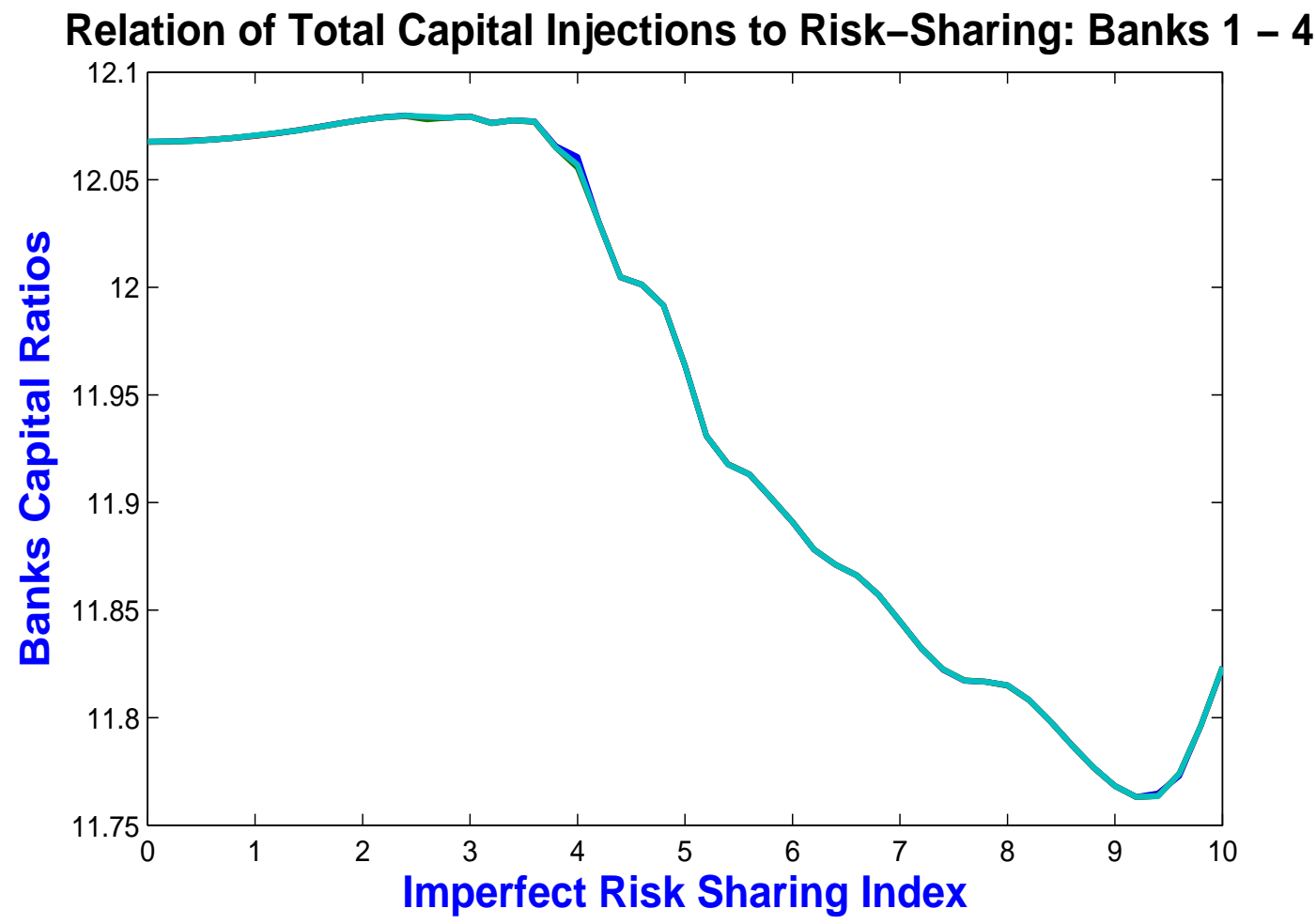

Notes: For the example in section 4, the figure presents the amount of capital that banks 1 to 4 have to hold as a function of the deviation from perfect risk sharing (the imperfect risk-sharing index) for banks 5 and 6 . The imperfect risksharing index runs from 0 to 10 . When it is 0 , the holdings of asset 1 are consistent with perfect risk sharing in which each banks exposure as a ratio of assets is equal to 1 . When the index is 10 , the ratio of exposure to assets for bank 5 is 5 . 